\title{
KINETICS OF THE RECEPTOR CURRENT IN BULLFROG SACCULAR HAIR CELLS ${ }^{1}$
}

\author{
D. P. COREY ${ }^{2}$ AND A. J. HUDSPETH ${ }^{3}$
}

Division of Biology, California Institute of Technology, Pasadena, California 91125

Received October 6, 1981; Revised September 9, 1982; Accepted November 23, 1982

\begin{abstract}
The receptor current of hair cells from the bullfrog's sacculus was measured by voltage clamp recording across the isolated sensory epithelium. Several hundred hair cells were stimulated en masse by moving the overlying otolithic membrane with a piezoelectrically activated probe. As measured by optical recording of otolithic membrane motion, the step displacement stimuli reached their final amplitudes of up to $1 \mu \mathrm{m}$ within $100 \mu \mathrm{sec}$. The relationship between displacement and steady-state receptor current is an asymmetric, sigmoidal curve about $0.5 \mu \mathrm{m}$ in extent. The time constant of the approach to steady state depends upon the magnitude of the hair bundle displacement and ranges from 100 to $500 \mu \mathrm{sec}$ at $4^{\circ} \mathrm{C}$; the time course is faster with larger displacements or at higher temperatures. Both the displacement-response curve and the kinetics of the response are changed by alterations in the $\mathrm{Ca}^{2+}$ concentration at the apical surface of the cells. The characteristics of the response are not consistent with simple models for the transduction process that involve enzymatic regulation of channel proteins or diffusible second messengers. Mechanical stimulation is instead posited to act directly by altering the free energy difference beween the open and closed forms of the transduction channel, thereby inducing a redistribution between these states. The dependences of the response kinetics on displacement and on temperature suggest that the thermal interconversion between open and closed transduction channels is limited by an enthalpy of activation of about $12 \mathrm{kcal} / \mathrm{mol}$.
\end{abstract}

A significant barrier to research on the mechanism of transduction by mechanoreceptor cells has been that the site of transduction is not clearly defined. Whereas the initial event in transduction by photoreceptors, for instance, is clearly the absorption of a photon by a molecule of visual pigment, mechanoreceptor systems are characterized by a chain of mechanical links that transmit the displacement stimulus to some molecular transduction

${ }^{1}$ This research was supported by Grants NS-13154 and GM-07616 from the National Institutes of Health and by the William Randolph Hearst Foundation, the Ann Peppers Foundation, the Pew Memorial Trust, and the System Development Foundation. We thank Dr. J. W. Moore for a computer simulation, Dr. W. K. Chandler and Mr. G. Yellen for an analytical treatment of current flow in stereocilia, Dr. J. H. R. Maunsell for help with computer programming, Mr. R. Jacobs for technical assistance and preparation of figures, and Ms. C. Katz for repeatedly typing the manuscript. We thank Dr. W. K. Chandler, Ms. R. A. Eatock, Dr. T. Holton, Mr. R. S. Lewis, and Mr. G. Yellen for comments on the manuscript.

${ }^{2}$ Present address: Department of Physiology, Yale University School of Medicine, New Haven, CT 06510.

${ }^{3}$ To whom reprint requests should be sent at Department of Physiology, University of California School of Medicine, San Francisco, CA 94143. element. Beyond this point, transduction is probably chemical in nature, leading directly or indirectly to a conductance change in the receptor cell membrane. The transduction element-what von Békésy (1960) termed "the final mechanical transformer"-remains as yet purely conceptual. It cannot be characterized, much less understood in molecular terms, until the intervening mechanical stages are either removed or well characterized themselves.

Our studies of the transduction process in vertebrate hair cells have heretofore been focused on direct stimulation (Hudspeth and Corey, 1977; Shotwell et al., 1981) and dissection (Hudspeth and Jacobs, 1979) of the mechanically sensitive hair bundles. In this way the magnitude of the conductance change that results from displacement of the stereocilia has been determined. The limited speed of both single-bundle stimulation and intracellular recording, however, precludes study of the temporal characteristics of the response. Vertebrate hair cells in particular have extremely rapid response times (Corey and Hudspeth, 1979a), a characteristic which produces an auditory sensitivity extending above 100 $\mathrm{kHz}$ in some animals (Sales and Pye, 1974).

In this paper we describe the kinetics of the conduct- 
ance change in response to fast mechanical stimuli, studied with the epithelial preparation of the bullfrog sacculus (Corey and Hudspeth, 1979a, 1983). Although the mechanical stimulation is somewhat less direct than in our previous studies, the intermediary mechanical links are characterized and are believed to contribute minimally to the measured relaxation times of the responses. If these relaxations can therefore be attributed to the transduction element, their characteristics suggest a particular class of possible models for transduction. A brief report of this study has appeared (Corey and Hudspeth, 1980a).

\section{Materials and Methods}

Preparation. All experiments used the epithelial preparation of the bullfrog saccular macula described in the preceding paper (Corey and Hudspeth, 1983). Care was taken to peel the otolithic membrane well past the region of the macula where the polarities of the hair cells reverse to prevent contamination of the response by hair cells oriented oppositely to those in the periphery. In order to increase the signal-to-noise ratio, a thin plastic film that reduced current flow from the unstimulated region was arranged closely around the stimulated region.

Solutions. In the basal chamber an elevated $\mathrm{K}^{+}$perilymph was used for all experiments. This depolarized hair cells to a low-resistance region of their currentvoltage relation (Corey and Hudspeth, 1983), so that changes in membrane current-in particular the receptor current-caused little change in membrane potential. This largely eliminated secondary currents due to voltage-sensitive conductances.

The apical chamber contained an artificial endolymph with $\mathrm{K}^{+}$as the principal cation. When high $\mathrm{Ca}^{2+}$ concentrations were used, the $\mathrm{K}^{+}$concentration was reduced to maintain a constant ionic strength.

Table I gives the ionic concentrations used in these solutions. All solutions contained $3 \mathrm{~mm} \mathrm{D}$-glucose and 5 mM HEPES buffer, and were adjusted to $\mathrm{pH} 7.2$ to 7.3 with $\mathrm{KOH}$ or $\mathrm{NaOH}$.

Recording. The current signal from the voltage clamp and the output of the optical stimulus monitor were lowpass filtered with a single-pole filter at $20 \mathrm{kHz}$ and a three-pole Bessel filter at $50 \mathrm{kHz}$, then digitized at 8 $\mu \mathrm{sec} /$ point before averaging. A stimulus set consisted of steps of 8 or 16 different amplitudes ranging from -0.7 to $1.0 \mu \mathrm{m}$, and of $1.5-$ to $4.0-\mathrm{msec}$ durations. Individual steps of different amplitudes were presented in random order at a rate of $6 \mathrm{~Hz}$, and 100 to 500 responses to steps of each amplitude were averaged. The interleaving proce-

TABLE I

Ionic composition of salines ${ }^{a}$

\begin{tabular}{|c|c|c|c|c|c|}
\hline & $\mathrm{K}^{+}$ & $\mathrm{Na}^{+}$ & $\mathrm{Ca}^{2+}$ & $\mathrm{Mg}^{2+}$ & $\mathrm{Cl}^{-}$ \\
\hline High $\mathrm{K}^{+}$perilymph & 17.0 & 106.9 & 1.36 & 0.68 & 128 \\
\hline Normal endolymph & 124.0 & 2.5 & 0.25 & & 127 \\
\hline $\mathrm{K}^{+} / 0.05 \mathrm{Ca}^{2+}$ & 129.9 & & 0.05 & & 130 \\
\hline $\mathrm{K}^{+} / 0.1 \mathrm{Ca}^{2+}$ & 129.7 & & 0.10 & & 130 \\
\hline $\mathrm{K}^{+} / 0.25 \mathrm{Ca}^{2+}$ & 129.3 & & 0.25 & & 130 \\
\hline $\mathrm{K}^{+} / 1 \mathrm{Ca}^{2+}$ & 127.0 & & 1.00 & & 129 \\
\hline $\mathrm{K}^{+} / 2 \mathrm{Ca}^{2+}$ & 124.0 & & 2.00 & & 128 \\
\hline $\mathrm{K}^{+} / 10 \mathrm{Ca}^{2+}$ & 100.0 & & 10.0 & & 120 \\
\hline
\end{tabular}

${ }^{a}$ Values are in millimolar concentrations. dure was intended to counteract effects of slow drift in response amplitude or any systematic effects of previous stimuli on the response.

In order to confirm that the motion of hair bundles closely follows that of the otolithic membrane to which they are attached, control experiments were performed in which a photomultiplier substituted for the usual photodiode as a monitor of displacement. The increased sensitivity afforded by the photomultiplier allowed the detection of displacement signals from individual hair bundles illuminated by a $100-\mathrm{W}$ microscope lamp system. For each measurement, the image of a hair bundle, magnified to roughly $\times 600$ with a compound microscope, was projected onto a slit aperture covering a plastic light guide attached to a photomultiplier tube (model 6655A, RCA, Harrison, NJ) operated at a supply voltage of 1,220 $\mathrm{V}$. The anode current signal, amplified 1000 times and low-pass filtered with a single-pole filter set at $100 \mathrm{kHz}$, was digitized at $2-\mu \mathrm{sec}$ intervals and averaged over about 10,000 repetitions (Corey and Hudspeth, 1983). Alternate measurements with identical stimuli were made at the edge of the stimulus probe or of a dense particle in the otolithic membrane.

Source of the recorded current. The generation of the microphonic current is described in the preceding paper (Corey and Hudspeth, 1983). Briefly, the voltage clamp, when compensated for the series resistance of the preparation, measures current that enters through the apical surfaces of hair cells and that leaves through the basolateral surfaces. Following a step increase in receptor current, a proportion of it passes through the basolateral hair cell surface as capacitive current and is measured by the clamp. The proportion is equal to the proportion of the total membrane capacitance contained in the basolateral surface, about $85 \%$ as estimated from measurements of the cellular surface area (including the stereocilia). As the receptor current begins to depolarize the cell, producing the intracellular receptor potential, the driving force for the current decreases. This change in the driving force has been minimized for the present experiments by exposing the basolateral cell surfaces to an elevated $\mathrm{K}^{+}$saline which depolarizes hair cells to a low-resistance region of their current-voltage relation. After the membrane capacitance has been charged, the receptor current is 90 to $95 \%$ of its value immediately following the step, and all of it passes through the basolateral surface as ionic current. The measured current accordingly changes from about $85 \%$ to about 90 to $95 \%$ of the total receptor current during the charging time of the hair cells. Moreover, this small change occurs over a time determined by the membrane time constant of 3 to $4 \mathrm{msec}$, which is slow compared to the signals studied here.

Ion accumulation in the restricted peribasal space during a step of receptor current might cause a $\mathrm{K}^{+}$-dependent depolarization of hair cells during the step. From the dimensions of the peribasal space measured with electron microscopy of the epithelium, however, one can estimate the concentration change following a pulse of outward $\mathrm{K}^{+}$current. In each cell, a 200-pA receptor current lasting for $10 \mathrm{msec}$ would raise $\left[\mathrm{K}^{+}\right]_{0}$ by $2 \mu \mathrm{M}$, which is nol significant. 
The adaptation mechanism (Eatock et al., 1979; Corey and Hudspeth, 1983) changes the receptor current over a period of tens to hundreds of milliseconds and is similarly of little consequence here.

The measured transepithelial currents are thus proportional to the conductance of the apical membranes of the hair cells, and the change in current following a mechanical stimulus reflects the opening of channels responsible for that conductance. The time course of the opening reflects the properties of the channels themselves and of mechanical or chemical stages preceding them in the transduction mechanism.

\section{Results}

Motion of the otolithic membrane. In the hair bundle of each hair cell, the mechanically sensitive stereocilia are closely attached to the bulbous tip of the kinocilium by a network of filamentous strands (Hillman and Lewis, 1971). The kinociliary bulb of each cell is similarly attached to the overlying otolithic membrane, an extracellular matrix about $20 \mu \mathrm{m}$ in thickness which extends over the whole of the macula. Normally the otolithic membrane is loaded with a mass of otoconia, whose greater density relative to that of the endolymphatic fluid causes the organ to be sensitive to linear acceleration. For these experiments, most of the otoconia were removed and the otolithic membrane was moved directly with a glass stimulus probe. The stimuli approximated step displacements of up to $1.0 \mu \mathrm{m}$ in amplitude and are shown in Figure 1.

The motion of the stimulus probe was measured optically (Corey and Hudspeth, 1980b, 1983). It has a sigmoidal rise occurring in about $80 \mu$ sec, followed by a transient oscillation of less than $3 \%$ of the step amplitude (Fig. 1A). There is no significant variation in form between positive and negative displacements; similarly, the form is unchanged if the probe is first subjected to a large negative step and then to a large positive step, or vice versa. Probe motion is not influenced by the temperature of the experimental preparation over the range 0 to $38^{\circ} \mathrm{C}$.

When the same optical monitor is focused at the edge of a residual clamp of otoconia on the otolithic membrane, an optical signal of similar waveform is seen (Fig. $1 B$ ). This signal is reversed in sign if the monitor is focused on the opposite edge of the clump. If the stimulus probe is lifted 1 or $2 \mu \mathrm{m}$ off the otolithic membrane, the optical signal vanishes at the same time that the electrical response of the macula disappears. The optical signal thus represents the motion of the otolithic membrane at the selected otoconial clump. For clumps near the stimulus probe, the waveform follows that of the probe within a few microseconds (Fig. $1 B$ ). Measured at clumps that are 70 to $100 \mu \mathrm{m}$ from the probe, the otolithic membrane motion is delayed at the midpoint of its rise by 20 to 30 $\mu \mathrm{sec}$ and is somewhat slowed in the completion of its rise. Near the edge of the stimulated region of macula, 150 to $200 \mu \mathrm{m}$ from the probe, the delay is increased to 50 to 60 $\mu$ sec. Figure $1 C$ is taken from this region of the otolithic membrane and thus indicates a worst case. Averaged over the whole of the stimulated region, then, the motion of the otolithic membrane lags that of the stimulus probe by about $40 \mu \mathrm{sec}$ and has a rise time of about $100 \mu \mathrm{sec}$.
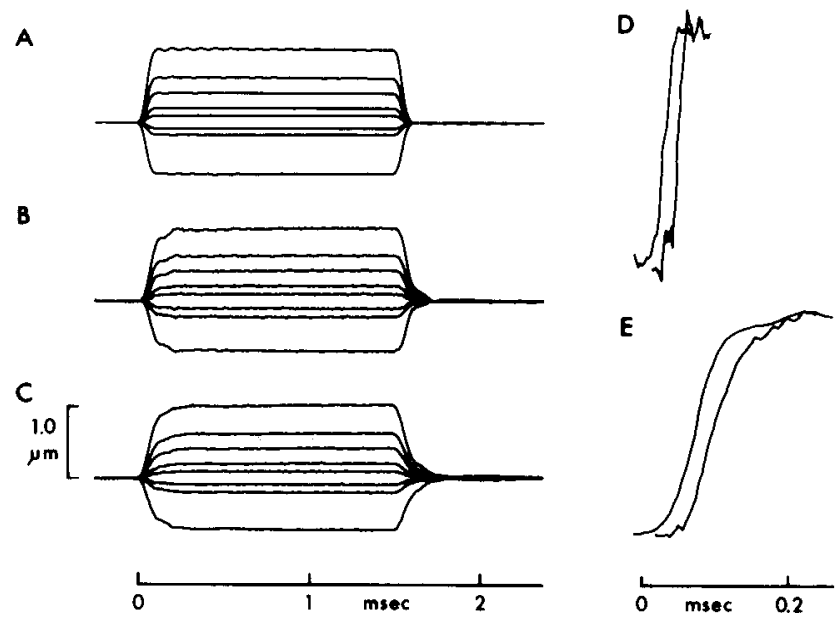

Figure 1. Motion of the stimulus probe and otolithic membrane. $A$, Motion of the stimulus probe was measured by focusing a spot of light on the edge of its tip and recording light not blocked by lateral displacement of the probe. The amplitude calibration was obtained separately by visual observation at $\times$ 1000 magnification. This record was obtained with the probe in contact with the otolithic membrane; there was no change when it was lifted off, indicating that the probe and stimulator are not significantly loaded by the otolithic membrane. 'I'he step amplitudes are (from the bottom) $-0.7,-0.2,-0.1,0.1,0.2,0.4$, 0.6 , and $1.0 \mu \mathrm{m}$ and constitute one of the standard test sets. $B$, Motion of the otolithic membrane was measured by focusing the light on a clump of otoconia adhering to the membrane near the probe. The oscillation in the probe motion is apparent in this record, but the rise and fall of the displacement are somewhat slowed. $C$, Motion of the otolithic membrane measured at a clump $150 \mu \mathrm{m}$ from the probe shows a more distinct slowing of the rising and falling phases; the oscillation is largely damped at this more distant position. As the probe was usually positioned in the middle of a $300-\mu \mathrm{m}$ patch, this record indicates a worst case for otolithic membrane settling. $D$, Motion of an individual hair bundle as measured by imaging it on the entrance diaphragm of a photomultiplier tube. The hair bundle's movement (right trace) lags that of the probe $100 \mu \mathrm{m}$ distant by about $20 \mu$ sec. $E$, Comparison of a rapid hair cell response with probe motion. The transepithelial current (right trace) evoked at $28^{\circ} \mathrm{C}$ by a $1-\mu \mathrm{m}$ step displacement of the otolithic membrane follows the probe motion by approximately $25 \mu \mathrm{sec}$.

No change in the rise time of the otolithic membrane motion is seen when the tissue is cooled to $4^{\circ} \mathrm{C}$.

The delay associated with propagation of displacements through the otolithic membrane to hair bundles has been studied in two ways. First, photomultiplier measurements of the motions of individual hair bundles yield a delay of only $20 \mu \mathrm{sec}$ at a distance of $100 \mu \mathrm{m}$ (Fig. $1 D)$. Second, the electrical response of the preparation at elevated temperatures follows probe motion with a delay of about $25 \mu \mathrm{sec}$, establishing this as an upper limit for propagation delays (Fig. $1 E$ ).

It might be that the response time of the otolithic membrane is fast, but that the amplitude of the displacement declines at positions successively farther from the probe. From microscopic observation of the otolithic membrane, it is clear that it moves, at least at long times, as a rigid sheet. Moreover, the optical signal following a maintained step shows no evidence of a slow creep to a 
final position. Thus we believe that essentially the full amplitude of the otolithic membrane's displacement is transmitted to all parts of the stimulated region.

The equilibrium displacement-response curve. We first measured the steady-state relation between conductance and the position of the hair bundles. Step displacements to 16 amplitudes ranging from $-0.55 \mu \mathrm{m}$ to $+0.95 \mu \mathrm{m}$ were presented; a positive displacement is defined as movement of a hair bundle toward its kinocilium, which increases the inward receptor current (Shotwell et al., 1981). The preparation was cooled to $4^{\circ} \mathrm{C}$ and the endolymphatic solution contained the normal $\mathrm{Ca}^{2+}$ concentration of $0.25 \mathrm{~mm}$. Under these conditions the currents settle to an equilibrium level in 0.5 to $2 \mathrm{msec}$ (Fig. 2A). Responses to the largest displacements decrease slightly over the next few milliseconds, which is attributable to the beginning of the adaptation process. The displacement record (Fig. $2 B$ ) is an optical signal from the otolithic membrane. The displacement-response curve, plotted as the peak level of the current versus the step size, is shown in Figure $2 C$. Several features of the curve are noteworthy. First, with the otolithic membrane in its resting position, the current flowing through the stimulus-sensitive conductance is 15 to $20 \%$ of the peak current evoked by saturating stimuli.
Perhaps not coincidentally, the resting position of hair cells is near the region of maximal sensitivity on the displacement-response curve. Second, the saturation is not symmetric, but is more abrupt for negative displacements than for positive ones. Finally, the range over which the current changes is rather narrow, slightly over half a micrometer.

The displacement-response curve measured in this preparation is quite similar to that measured by direct stimulation of single hair bundles (Shotwell et al., 1981) in its operating range, asymmetry, and resting bias. We therefore believe that the otolithic membrane faithfully transmits the full amplitude of the mechanical stimulus to the hair bundles.

Kinetics of the approach to equilibrium. The current records of Figure $2 A$ illustrate an additional feature of the response: the approach to equilibrium is more rapid for large displacements than for small ones. This is examined at an expanded time scale in Figure $3 A$; again, the displacement record (Fig. $3 B$ ) shows the otolithic membrane motion. The onset of all traces is fairly sharp and occurs during the rise of the otolithic membrane displacement. At higher temperatures $\left(28^{\circ} \mathrm{C}\right)$ the response to large displacements $(1 \mu \mathrm{m})$ has the waveform of the otolithic membrane motion signal and follows it
A

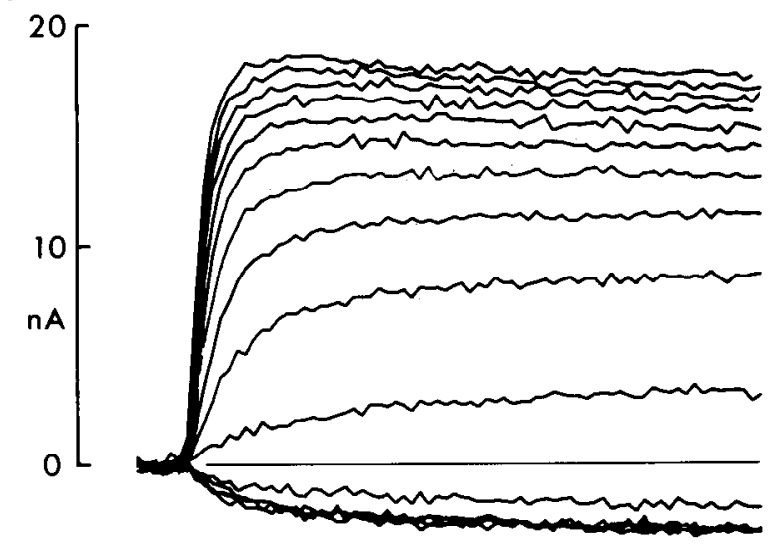

B

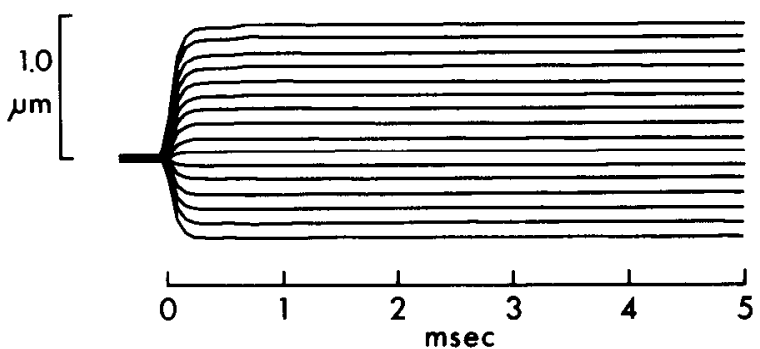

C

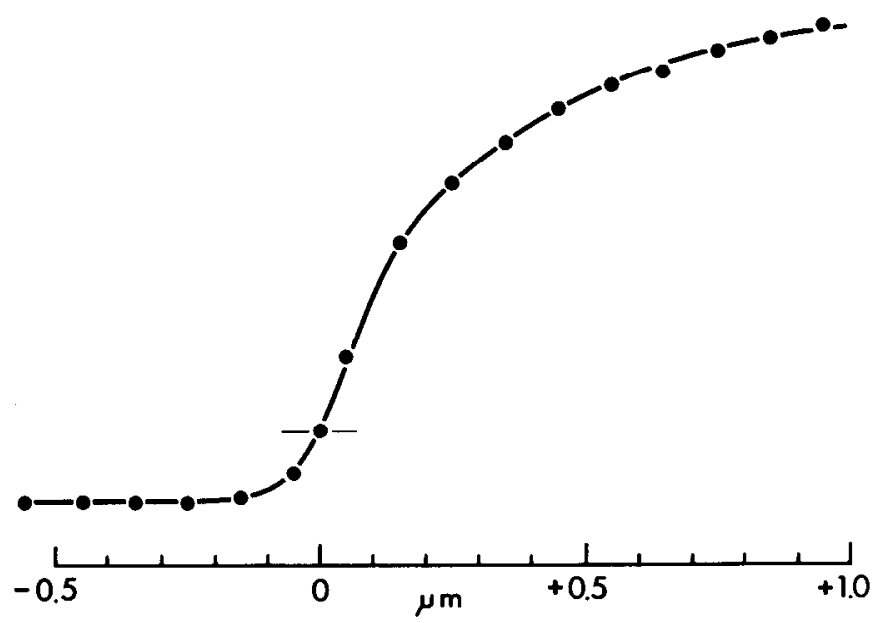

Figure 2. Measurement of the equilibrium displacement-response curve. $A$, Transepithelial current was evoked by a set of 16 test steps; inward receptor current (from apical to basal surfaces of the epithelium) is shown as upwards. The peak amplitude of the evoked current varied considerably among preparations and was roughly correlated with the area of otolithic membrane left coupled to hair cells. $B$, Motion of the otolithic membrane was measured optically at a site $150 \mu \mathrm{m}$ from the stimulus probe. $C$, The equilibrium displacement-response curve relates the peak evoked current for each step to the amplitude of the step. The smooth curve was generated from a model discussed subsequently in the text. Although the ordinate (current) scale varies among preparations, the shape of the curve does not. Moreover, the shape is quite similar to that measured with direct stimulation of single bundles. Apical $\mathrm{Ca}^{2+}, 0.25 \mathrm{~mm} ; 4^{\circ} \mathrm{C}$. 
A

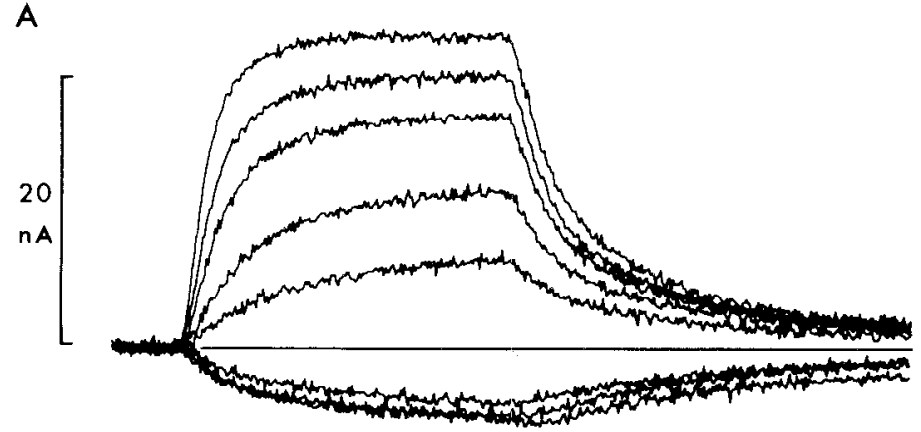

B

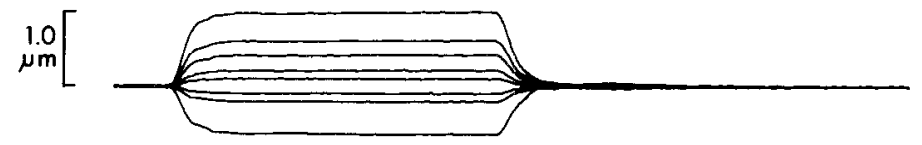

C

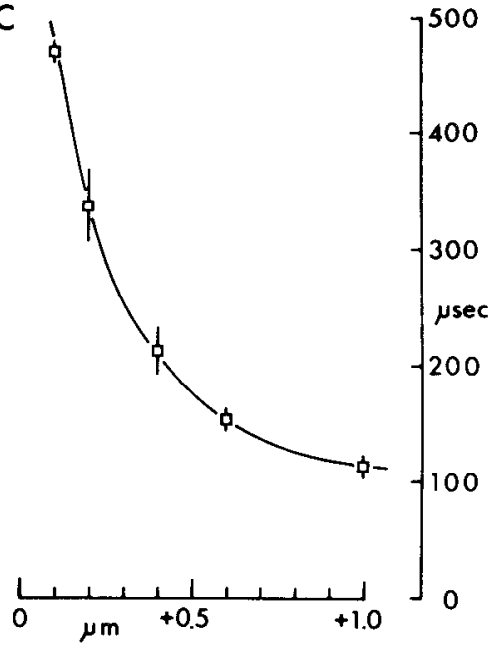

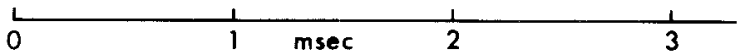

Figure 3. Time course of the approach to equilibrium. A, The transepithelial currents evoked by a set of eight test steps display an approach to their new equilibrium values that can be fitted with single-exponential curves, in each case in which the current increases from rest. The decline of current with negative displacement or following termination of a positive test step requires at least two exponential terms to be fitted. $B$, Motion of the otolithic membrane was measured $150 \mu \mathrm{m}$ from the stimulus probe, and thus indicates the maximum settling time for the mechanical stimulus. Step amplitudes are as in Figure 1. $C$, Time constants of the approach to equilibrium are plotted against the displacement, as averages from several preparations with bars indicating standard errors of the means. For the largest steps, time constants were measured from the portion of the curve recorded after the otolithic membrane had settled. The smooth curve was drawn by eye. Apical $\mathrm{Ca}^{2+}, 0.25 \mathrm{~mm} ; 4^{\circ} \mathrm{C}$.

by about $25 \mu$ sec (see also Figs. $1 D$ and 6 ). Thus hair bundle deflection follows motion of the overlying otolithic membrane with only a slight delay; the time course of the response at $4^{\circ} \mathrm{C}$ is determined primarily by processes subsequent to the deflection of hair bundles. For each trace in which the current increases from the resting level, the curve can be well fitted with a single exponential function. The time constants of the exponentials differ considerably, however, and are plotted as a function of displacement in Figure $3 \mathrm{C}$. Time constants at $4^{\circ} \mathrm{C}$ range from 100 to $500 \mu$ sec, indicating rates as fast as or faster than those of any other biological channel yet studied (Hodgkin and Huxley, 1952; Hille, 1971; Chiu et al., 1979).

The waveforms become more complex, however, if the otolithic membrane is first stepped to large positive or negative positions (Fig. 4). Following a prepulse to -0.4 $\mu \mathrm{m}$, the responses to steps back to the resting position or to small positive positions show a delay of as much as $200 \mu \mathrm{sec}$ before the rise (Fig. $4 B$ ). For some traces, the onset does not begin until well after the otolithic membrane has settled. A sigmoidal onset of this sort requires at least two time constants to be fitted. The delay for transitions to larger positive positions is much smaller and the traces can be nearly superimposed (when scaled vertically) on transitions from rest.

No such delay is seen when the prepulse is to large positive positions (Fig. $4 \mathrm{C}$ ). The offset traces begin at the same point; the slight rounding at the corner is commensurate with the rise time of the probe. Fitting these records, however, also requires two time constants, a shorter one of about $150 \mu \mathrm{sec}$ and a longer one of 500 to $800 \mu \mathrm{sec}$. The offset rates, surprisingly, do not seem to increase with larger negative displacements. The current records for steps to $-0.2,-0.4$, and $-0.7 \mu \mathrm{m}$ exactly superimpose in this figure and for all preparations studied under these conditions.

The time constants extracted from these traces are plotted against displacement in Figure' 5 . Time constants for positive-going displacement steps following the negative prepulse were measured from the upper portion of each lrace and with a variable delay and thus approximately equal the time constants of the rate-limiting steps in the process of settling to a new equilibrium. The portion of each trace measured thus occurs after the otolithic membrane has reached its new position. The time constants for steps from $-0.4 \mu \mathrm{m}$ to positive positions are the same as those from rest; the difference occurs in the delay before the rise when the negative prepulse is given.

Time constants for the offset following a positive prepulse were measured beginning at the midpoint of the otolithic membrane signal, an arbitrary choice that was found to give the best fits to the initial segments of the offset traces. Traces were fitted by summing two exponential curves: a smaller, fast relaxation and a slower relaxation of about 3 times the amplitude. The measured time constants confirm the independence of the offset rates on displacement for steps to negative bundle positions. Notice also that the slow offset rates become displacement insensitive only at positions negative to $-0.1 \mu \mathrm{m}$, the same point where the negative saturation occurs.

Variation of the kinetics with temperature. When the preparation is warmed to room temperature, the approach to equilibrium is considerably faster (Fig. 6). The 


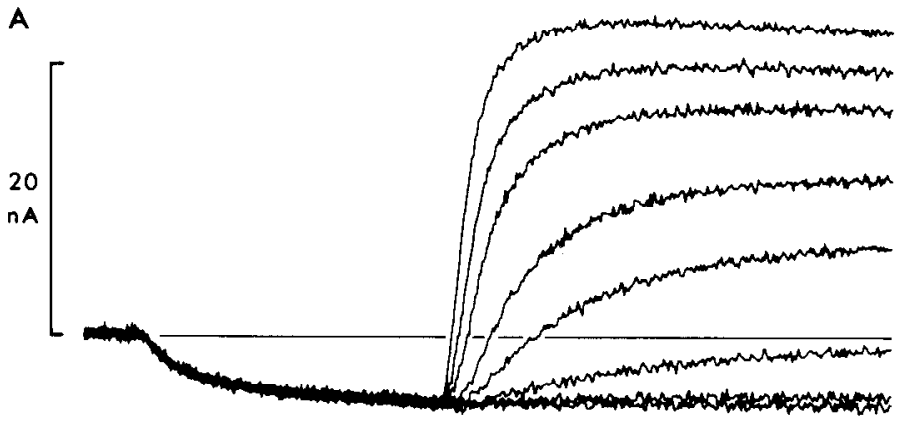

B

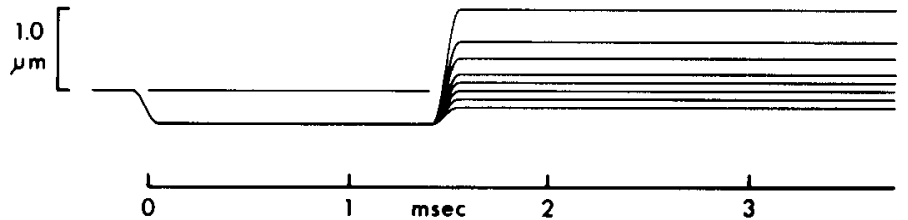

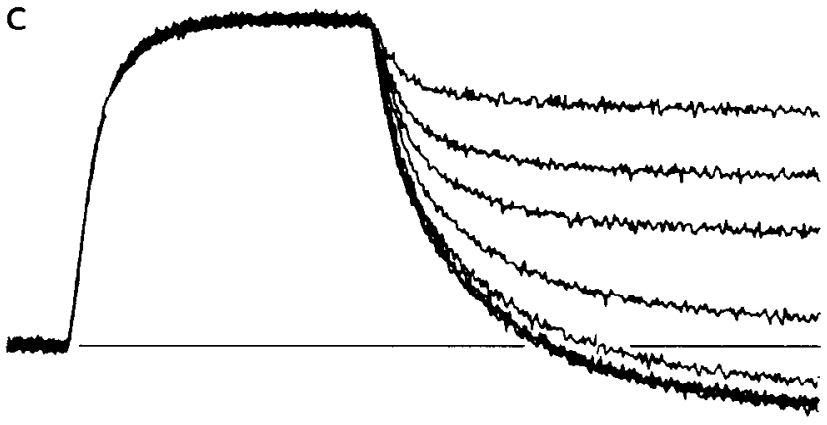

D

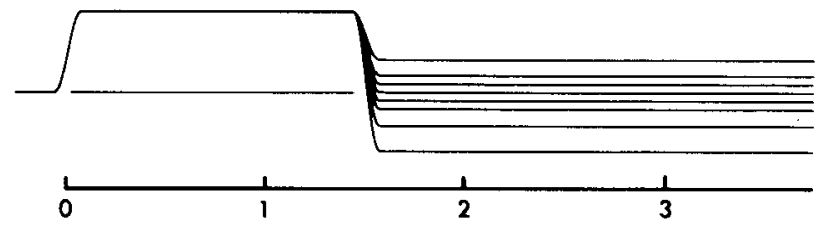

Figure 4. Time course of the approach to equilibrium with a negative or positive prepulse. The preparation is the same as that in Figure 3. $A$, The onset of currents following a negative prepulse to $-0.4 \mu \mathrm{m}$ shows a delay before the rise but is well fitted by a single exponential following the delay. $R$, The motion of the otolithic membrane was not measured in this instance but was drawn to show the approximate time course of the probe motion averaged over the stimulated region. Steps are to $-0.2,-0.1,0$, $0.1,0.2,0.4,0.6$, and $1.0 \mu \mathrm{m}$. $C$, The offset of currents following a positive prepulse to $1.0 \mu \mathrm{m}$ shows no delay, but the relaxations require a sum of at least two exponential functions to be fitted. Note that the currents following steps to $-0.7,-0.4$, and $-0.2 \mu \mathrm{m}$ have identical time courses. $D$, Otolithic membrane motion was drawn to indicate the pulse protocol. Steps are to $-0.7,-0.4$, $-0.2,-0.1,0,0.1,0.2$, and $0.4 \mu \mathrm{m}$. Apical $\mathrm{Ca}^{2+}, 0.25 \mathrm{mM} ; 4^{\circ} \mathrm{C}$.

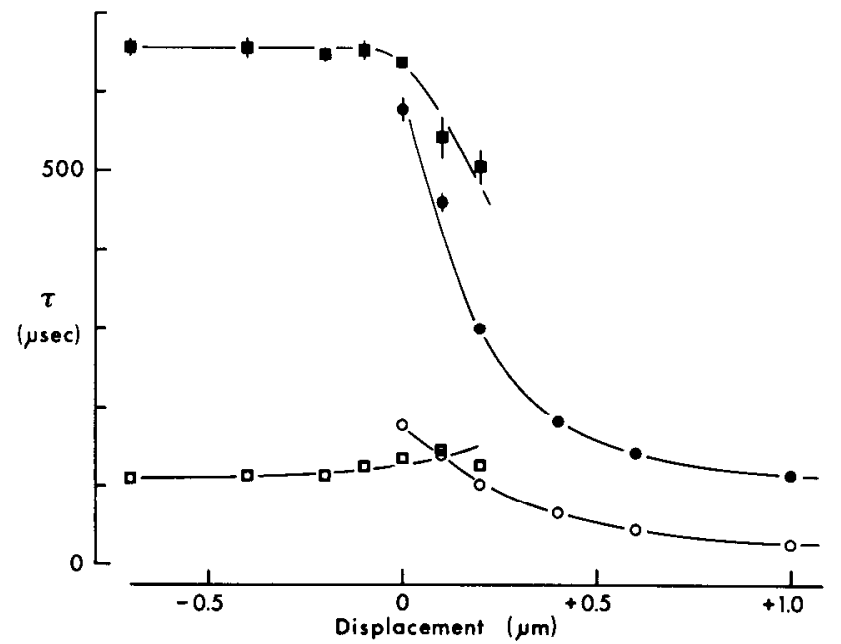

Figure 5. Time constants of the relaxations of receptor current with a prepulse protocol. Data are plotted as averages with bars indicating standard errors, and with $N$ ranging from 2 to 10. The onset of current with positive steps was fitted with a single exponential curve, with a time constant (O) beginning after a variable delay $(O)$ measured from the midpoint of the otolithic membrane rising phase. The offset of current was fitted by a sum of two exponential functions, both beginning at the midpoint of the motion. The faster component (time constant $\square$ ) had an amplitude roughly one-third that of the slower component (time constant $\square$ ). This description of the time course of the relaxations gave fits that were quite satisfactory by eye, but it is clearly not a unique description of the currents. Smooth curves through the data were drawn by eye.

fastest onsets are then not much slower than the motion of the otolithic membrane. The general features of the response remain: steps to small displacements give slower responses than those to larger displacements, the onset following a negative prepulse has a sigmoidal rise, and the offset records are characterized by two time constants. In Figure $6 A$, the decrease in the current amplitude following the larger steps is more noticeable since the adaptation is faster. Also, the traces for steps to $0 \mu \mathrm{m}$ in Figure 6, $A$ and $B$ do not return to zero following the prepulses, but overshoot as a consequence of the slight adaptation occurring during the 1.5-msec prepulses.

In this preparation the resting current is less as a proportion of the total than that seen in Figure 2. There is some variation among preparations in the proportion of receptor current flowing at rest, possible causes of which will be explored below. No systematic variation in this parameter was seen with temperature changes, however, nor did the shape of the displacement-response curve change systematically.

Figure 7 shows the time constants of some selected transitions, plotted as a function of temperature in an Arrhenius plot. The onset rates for the transition from $-0.4 \mu \mathrm{m}$ to $+0.2 \mu \mathrm{m}$ increase monotonically with temperature with a relation that is linear in an Arrhenius plot (Fig. $7 A$ ). If the mechanism responsible for the limiting relaxation rate is a first-order rate process, the dependence on temperature of its rate constant $k$ and the time constant $\tau$ is given by

$$
k=1 / \tau=f \exp (-\Delta G / R T)
$$

in which $\Delta G=\Delta H-T \Delta S . \Delta G$ is an activation energy, with an enthalpic component $\Delta H$ and an entropic component $T \Delta S$. $f$ is a frequency factor of approximately 6 $\times 10^{12} \mathrm{sec}^{-1}$, and $R$ and $T$ have their usual meanings. The slope of the Arrhenius plot then gives the enthalpy of activation, here equal to $11.1 \mathrm{kcal} / \mathrm{mol}$. Rates for transitions to $0.1 \mu \mathrm{m}$ and $0.0 \mu \mathrm{m}$ are also linear on an Arrhenius plot, and indicate enthalpies of 13.1 and $13.5 \mathrm{kcal} / \mathrm{mol}$, 


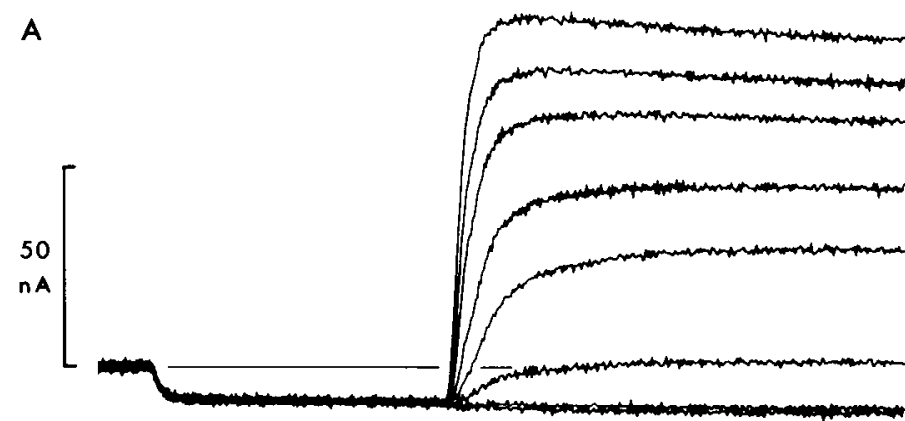

B
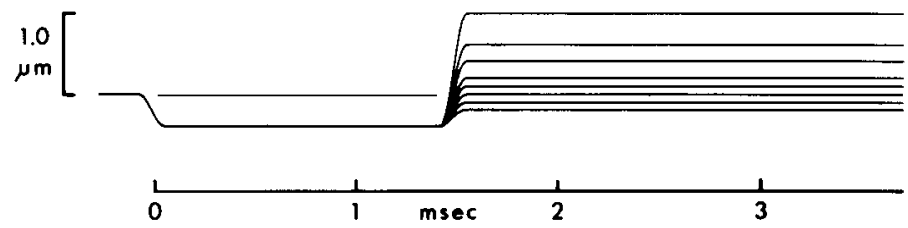

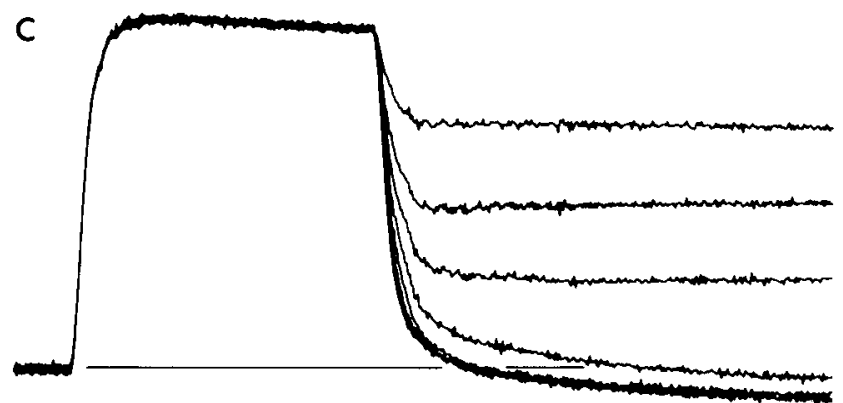

D

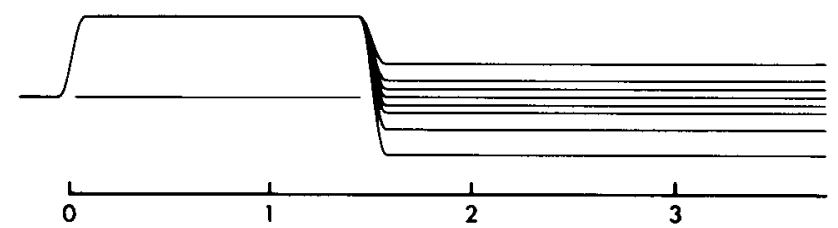

Figure 6. Time course of the currents measured at $21.1^{\circ} \mathrm{C}$. The preparation and the temperature are different from those in Figure 4, but the protocol is the same in all other respects. The time course of the approach to equilibrium clearly varies with displacement, but at this temperature the fastest relaxations cannot reliably be distinguished from the settling of the otolithic membrane. Apical $\mathrm{Ca}^{2+}, 0.25 \mathrm{~mm}$.
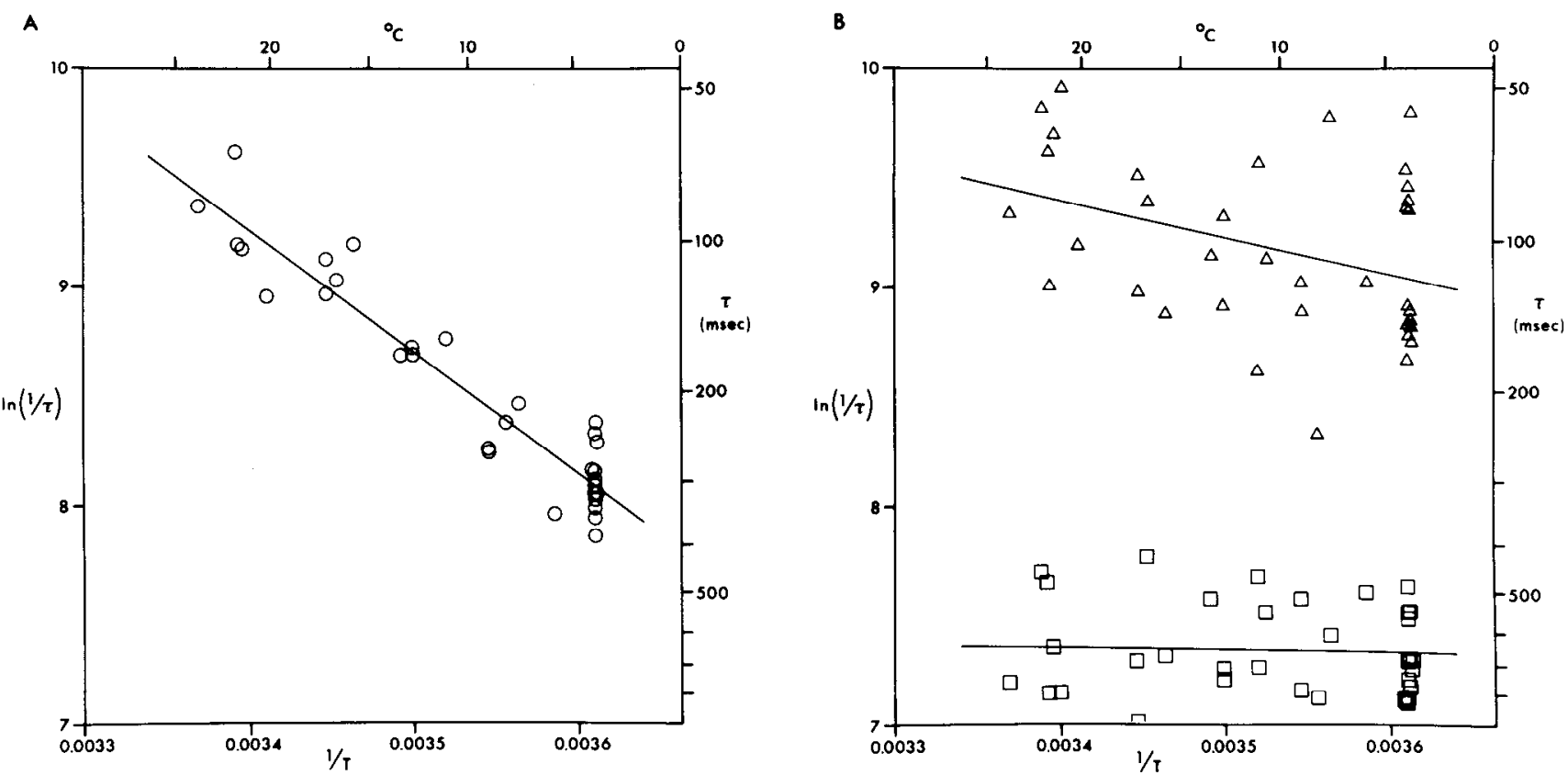

Figure 7. Temperature dependence of the kinetics. Time constants of fits to individual trials are plotted against temperature in an Arrhenius plot. $A$, The natural logarithm of the reciprocal of the time constant $(\tau)$ for the onset of current in response to a step from -0.4 to $+0.2 \mu \mathrm{m}$ varies inversely with the reciprocal of absolute temperature. The line is a least-squares fit to the data; its slope is consistent with an enthalpy of activation of $11.1 \mathrm{kcal} / \mathrm{mol}$. $B$, The fast $(\triangle)$ and slow ( $\square$ ) time constants for the offset of current following a step from $+1.0 \mu \mathrm{m}$ to $-0.7 \mu \mathrm{m}$ are much less temperature sensitive. Although the scatter in the data is greater, the least-squares fits show no significant variation of time constant with temperature.

respectively. Rates for transitions to $0.4,0.6$, and $1.0 \mu \mathrm{m}$ are too fast at higher temperature to be separated with confidence from the otolithic membrane motion, but show a similar dependence on temperature at lower temperatures. These values for enthalpy may be expressed alternatively as a $Q_{10}$ of 2.0 to 2.2 .

The offset rates seem much less dependent on temperature (Fig. $7 B$ ). This is surprising, because Figures 4 and 6 clearly show a faster offset at $21^{\circ} \mathrm{C}$ than at $4^{\circ} \mathrm{C}$. In fact, the temperature dependence is primarily a consequence, in this fitting procedure, of a change in the amplitudes of the two components rather than in their time constants. At $4^{\circ} \mathrm{C}$ the slow component is responsible for $88 \%$ of the offset to negative positions; at $21^{\circ} \mathrm{C}$ it accounts for only $28 \%$. One possibility is that the reduction in current following a negative step is caused by two separate processes, the faster of which becomes more important at higher temperatures. Another possibility is discussed below.

The effect of altered $\mathrm{Ca}^{2+}$ concentration. The trans- 
duction process of vertebrate hair cells apparently requires calcium ions in the fluid bathing the hair bundle (Sand, 1975; Hudspeth and Corey, 1977; Corey and Hudspeth, 1979b). The concentration of free $\mathrm{Ca}^{2+}$ is only 30 $\mu \mathrm{M}$ in the endolymph of a mammalian cochlea (Bosher and Warren, 1978) and $260 \mu \mathrm{M}$ in that of the bullfrog's sacculus (J. R. Maunsell, R. Jacobs, and A. J. Hudspeth, unpublished results). The effect of $\mathrm{Ca}^{2+}$ concentration on the rate of the adaptation of the transduction process has already been noted (Eatock et al., 1979).

There is an additional effect of apical $\mathrm{Ca}^{2+}$ concentration on the transduction mechanism: it shifts the displacement-response curve along the displacement axis. Figure 8 shows displacement-response curves measured in six calcium concentrations ranging from $50 \mu \mathrm{M}$ to 10 $\mathrm{mM}$. The proportion of peak current that is activated at rest changes from $52 \%$ in low calcium to $8 \%$ or less in high calcium. If the change in resting bias is measured as a shift along the displacement axis, the shift is seen to depend logarithmically on calcium concentration, moving by $0.1 \mu \mathrm{m}$ for each 10 -fold increase in $\mathrm{Ca}^{2+}$ (Fig. $8 B$ ). The effect is readily reversible: in this experiment the concentration was returned to the normal $0.25 \mathrm{~mm}$ following the series of test solutions, and the displacement-response curve could be exactly superimposed on the curve previously measured at that concentration. The effect is seen within a minute or so of changes in the solution bathing the apical ends of the cells. It does not occur with comparable changes in $\mathrm{Ca}^{2+}$ concentration in the artificial perilymph bathing the basolateral cell surfaces.

In addition, the amplitude of the peak receptor current decreases at higher calcium concentrations. This need not reflect a direct effect of $\mathrm{Ca}^{2+}$ on the transduction mechanism, as the decrease in response amplitude may be explained by three other factors. First, the concentration of $\mathrm{K}^{+}$, the ion which carries most of the receptor current under these conditions, is reduced by $23 \%$ in the highest $\mathrm{Ca}^{2+}$ saline solution to maintain constant tonicity. Second, $\mathrm{Ca}^{2+}$ or any other divalent cation would be expected to reduce the negative surface charge on the membrane by screening; this in turn would decrease the concentration of permeant monovalent cations at the membrane surface and thus reduce the receptor current. If there were a charge density of 1.0 electron charges/ $\mathrm{nm}^{2}$ on the external surface of the membrane near the channels, the surface potential would be lowered by 22 $\mathrm{mV}$ when $\mathrm{Ca}^{2+}$ is raised from 0.1 to $10 \mathrm{~mm}$ (McLaughlin et al., 1971; Muller and Finkelstein, 1972; Hille et al., 1975). The potassium activity at the membrane would then be reduced to $42 \%$ of its value in low calcium. Third, although $\mathrm{Ca}^{2+}$ passes through the transduction channel (Corey and Hudspeth, 1979b), it may also act as a partial blocker, as it does in the acetylcholine receptor channel at the frog motor endplate (Lewis, 1979).

The shift in the displacement-response curve is not itself a charge-screening phenomenon, however. When $10 \mathrm{mM} \mathrm{Sr}^{2+}$ is added to the normal $0.25 \mathrm{mM} \mathrm{Ca}^{2+}$ saline, the amplitude of the peak receptor current declines, but the curve does not shift. If instead the normal $\mathrm{Ca}^{2+}$ is replaced with $\mathrm{Sr}^{2+}$, then the curve shifts to the left.

Finally, the displacement-response curve shifts to the left by about $0.1 \mu \mathrm{m}$ when $\mathrm{K}^{+}$in the apical solution is replaced with $\mathrm{NH}_{4}^{+}$, another permeant cation. When $\mathrm{NH}_{4}^{+}$ is washed out, the curve rebounds to the right before returning to the normal position. This suggests that the process may be mediated or modified by intracellular $\mathrm{pH}$ (Roos and Boron, 1981).

It would be interesting to know, therefore, whether the
A

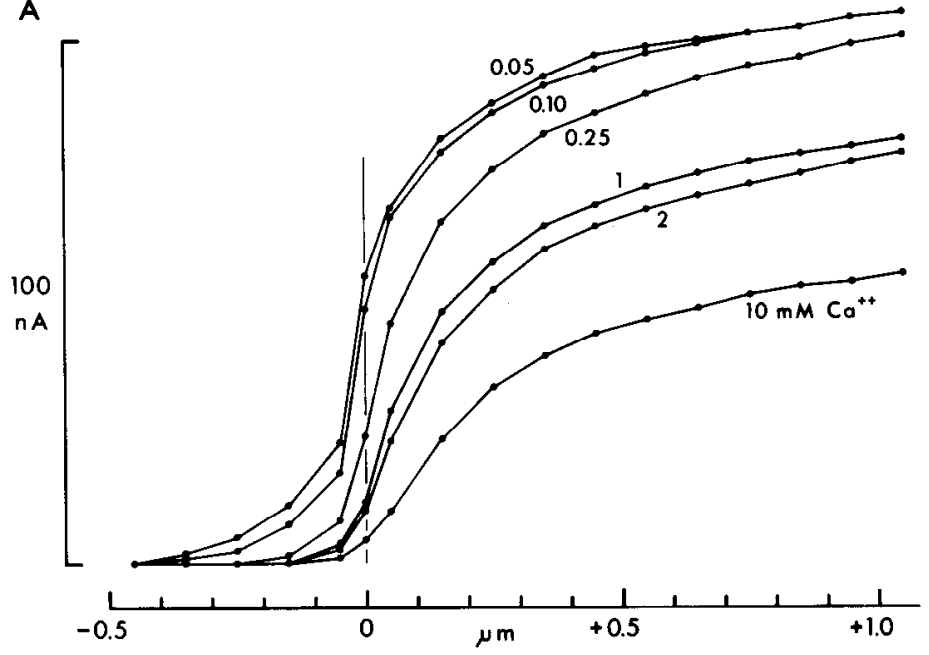

B

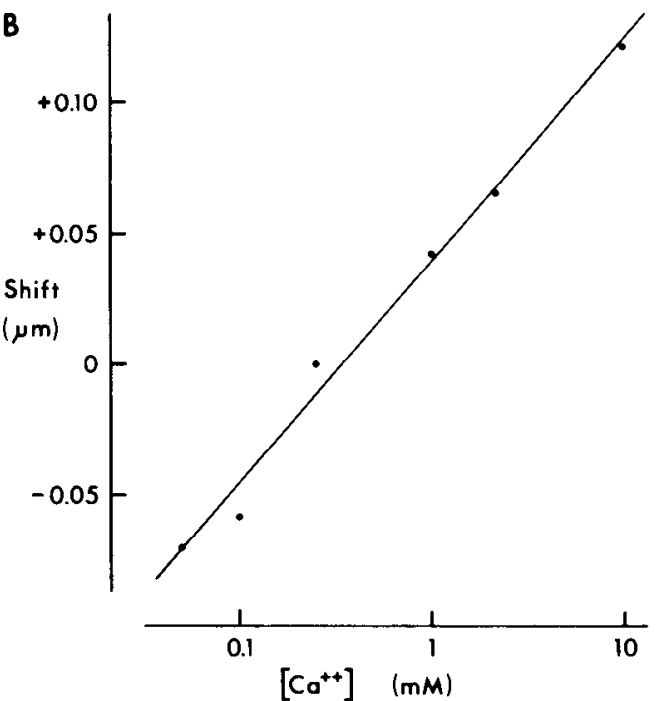

Figure 8. Shift in the displacement-response curve with altered apical $\mathrm{Ca}^{2+}$ concentration at $22^{\circ} \mathrm{C}$. $A$, Displacement-response curves were measured as shown in Figure 2 and their values at large negative displacements were aligned for comparison. In this experiment the apical $\mathrm{Ca}^{2+}$ concentration was initially $0.25 \mathrm{~mm}$, was then changed sequentially from $0.05 \mathrm{~mm}$ to $10 \mathrm{~mm}$ with several minutes equilibration between measurements, and was finally returned to $0.25 \mathrm{~mm}$. The shift was completely reversible over several such series in this preparation and has been repeated with similar results but with fewer concentrations in many other preparations. The diminution of maximum current at high $\mathrm{Ca}^{2+}$ concentrations is similarly reversible. $B$, The shift in the displacement-response curve, measured as the change in the displacement required to activate half the maximum current, depends logarithmically on apical $\mathrm{Ca}^{2+}$ concentration. Data are taken from $A$; displacements are measured relative to the curve in $0.25 \mathrm{mM} \mathrm{Ca}^{2+}$. 
effect of calcium and of ammonium can be viewed in all respects as a simple shift of the transduction mechanism along the displacement axis. Is the dependence of the time constants on displacement similarly shifted? Representative records in low and high $\mathrm{Ca}^{2+}$ are shown in Figure 9, and the extracted time constants in Figure 10. For comparison, smooth curves representing the values of time constants in $0.25 \mathrm{~mm} \mathrm{Ca}{ }^{2+}$ are included in Figure 10.

In low $\mathrm{Ca}^{2+}$ saline, the time constant of relaxation for positive steps is smaller at each bundle position, which is qualitatively consistent with a simple shift to the left of the $\tau$ versus displacement curve. In the high $\mathrm{Ca}^{2+}$ solution, however, the time constants are also smaller than in normal $\mathrm{Ca}^{2+}$, a change opposite to that predicted by supposing a simple shift. Nor can the effect on the time constants for negative-going steps be explained as a simple shift. In low $\mathrm{Ca}^{2+}$, the slower time constant begins to plateau at a displacement more negative than in normal $\mathrm{Ca}^{2+}$, as expected, but the plateau value of $\tau$ is much larger (the offset is slower). In high $\mathrm{Ca}^{2+}$ the plateau occurs at more positive displacements, but the offset is faster. The faster time constant of the offset also seems to decrease in higher $\mathrm{Ca}^{2+}$, but this effect may not be significant.

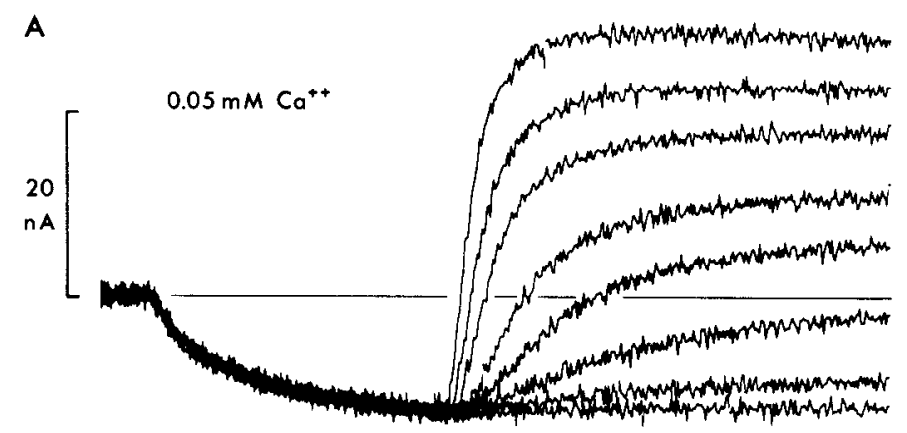

B

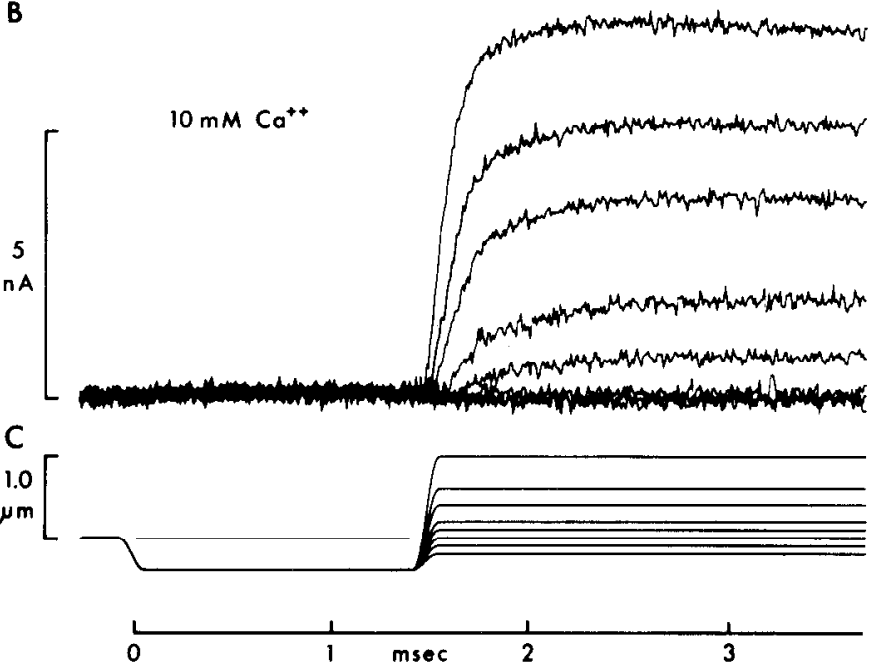

The effect of calcium on the relaxation rates is thus more complicated than a shift along the displacement axis. There are, nevertheless, some consistencies in the effect. At all calcium concentrations the slower time constant of the offset increases with steps to more negative positions, but then levels off. The point at which the time constant becomes independent of displacement is roughly the same as the point of negative saturation of the displacement-response curve. In the region in which the slow time constant is displacement sensitive, however, it seems independent of $\mathrm{Ca}^{2+}$ concentration.

\section{Discussion \\ Possible sources of artifact}

Before considering the implications of these data for a model of the transduction process, we should first assess the possible sources of error in the measurements.

The optical displacement monitor measures the motion of otoconial clumps on the upper surface of the otolithic membrane; the lower surface, to which hair bundles are coupled, might not follow this motion instantaneously. Since the otolithic membrane is clearly stiff to lateral displacements, it seems unlikely that this morphologically homogeneous material shows significant shear from top to bottom.
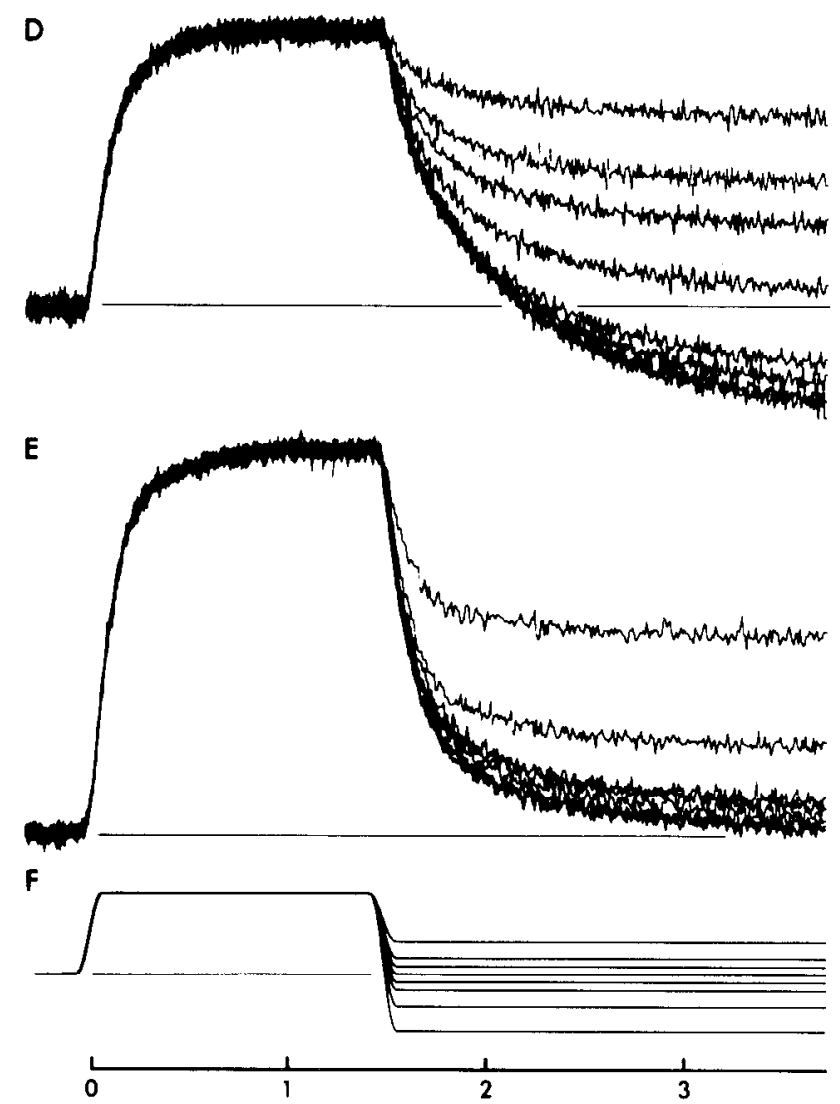

Figure 9. Effects of low and high apical $\mathrm{Ca}^{2+}$ concentration on the kinetics. $A$ and $D$, Responses to the standard test sets were recorded with $0.05 \mathrm{~mm}$ apical $\mathrm{Ca}^{2+}$. The proportion of current active at zero displacement is considerably larger than that with normal $\mathrm{Ca}^{2+}$. The onset of current following a step to a given displacement is faster, and the offset slower, than in normal $\mathrm{Ca}^{2+}$ (cf. Fig. 4), $B$ and $E$, Responses recorded in $10 \mathrm{mM} \mathrm{Ca}^{2+}$ show virtually no receptor current flowing at rest. Here also, the onset of currents is faster than in normal $\mathrm{Ca}^{2+}$, as is the offset of currents. The preparation is different from that shown in $A$ and $D$. $C$ and $F$, Otolithic membrane motion was drawn to indicate the pulse protocol and approximate time course of the displacements. The temperature was $4^{\circ} \mathrm{C}$. 
A

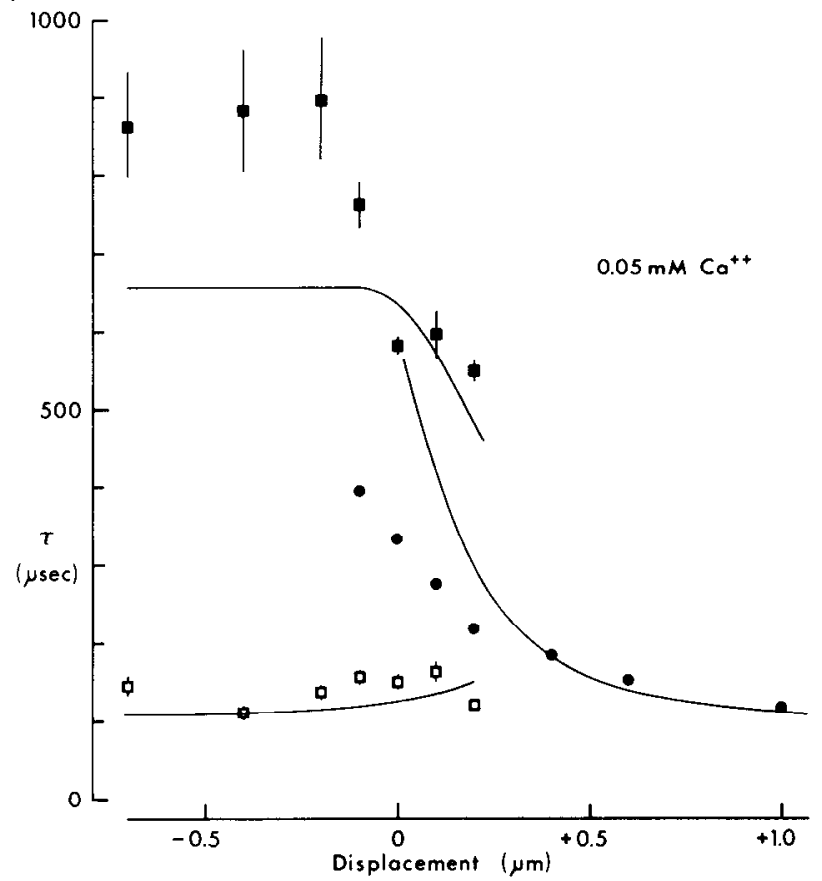

B

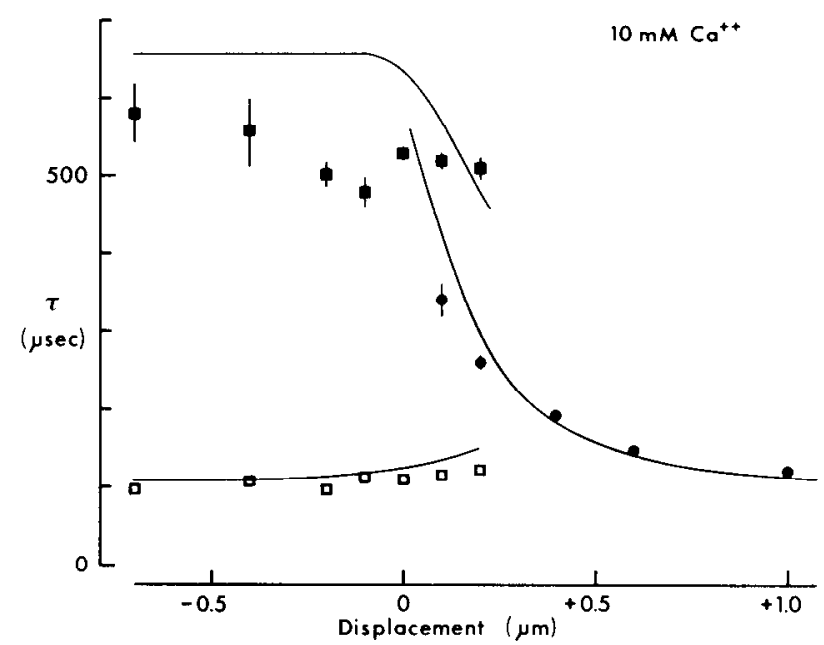

Figure 10. Time constants of the relaxations in low $(0.05 \mathrm{~mm} ; A)$ and high $\mathrm{Ca}^{2+}(10 \mathrm{~mm} ; B)$, plotted against the final displacement. An exponential function with a single time constant (O) and a delay was fitted to each onset trace in Figure 9 , $A$ and $B$; the offset traces (Fig. $9, D$ and $E$ ) were fitted with the sum of fast ( $\square$ ) and slow ( $\square$ ) exponential functions. The smooth curves drawn through the data in Figure 5 are reproduced here for comparison.

Although the motion of the otolithic membrane has been measured directly, it is not clear that the hair bundles follow this motion instantaneously. The similarity of the displacement-response curve measured here to that measured intracellularly with direct bundle displacement suggests that the equilibrium positions of bundles and otolithic membrane are the same. Al higher temperatures, the recorded current follows the otolithic membrane motion closely and the otolithic membrane motion is not temperature sensitive. It might be, though, that at $4^{\circ} \mathrm{C}$ much of the relaxation of currents to their equilibrium values is caused by mechanical relaxation of the bundles occuring over 100 to $500 \mu$ sec. The bond seen morpholugically between each kinocilium and the contiguous stereocilia makes this less likely, but it remains unclear how tightly the stereocilia are linked to one another.

An analysis of the fluid mechanics of the preparation, however, supports the idea that the motion of hair bundles is tightly coupled to that of the otolithic membrane. For objects the size of hair bundles, moving at the velocities imposed in this study through a medium of the viscosity of water, the Reynolds number $R_{\epsilon}$ is much less than 1:

$$
R_{e}=u_{0} l / v=0.06
$$

where the velocity $u_{0}$ is $1 \mathrm{~cm} / \mathrm{sec}$, the characteristic length $l$ is $10 \mu \mathrm{m}$, and the kinematic viscosity of water $v$ is $0.016 \mathrm{~cm}^{2} / \mathrm{sec}$ at $4^{\circ} \mathrm{C}$. Momentum is consequently negligible in comparison to viscosity, and the force on endolymph and hair bundles is predominantly viscous drag. At low Reynolds numbers, and at long times, the velocity of fluid between two plane surfaces shearing relative to one another increases linearly above the fixed surface (Couette flow; Sabersky et al., 1971), which is in this case the apical surface of the epithelium. The force applied to flexible elements extending from that surface would move them as straight rods bending at their bases. Calculations indicate that the linear flow profile is established in about $20 \mu \mathrm{sec}$ (Budak et al., 1964; Sabersky et al., 1971). Thus, on the time scale relevant to this study, the filamentous coupling from the otolithic membrane to hair bundles should be augmented and not opposed by hydrodynamic coupling; the results of control experiments (Fig. 1) are consistent with this expectation.

Individual hair cells might have different resting biases, or the stimulus probe might slowly drift in position during an experiment. Records would then be distorted by a smear of apparent displacements. Intracellular recording reveals a reasonable homogeneity of resting biases of hair cells in the peripheral macula (A. J. Hudspeth, unpublished observation), arguing against the former objection. The existence of the adaptation mechanism (Eatock et al., 1979; Corey and Hudspeth, 1983) probably mitigates the latter difficulty, as the effective bias on transduction elements of each cell relaxes to a common rest position within seconds.

A similar spread in displacement sensitivities might occur among cells, or even among transduction elements of single cell. However, the variation among cells is probably small. Bundle orientations are spread over no more than $80^{\circ}$ in the peripheral region from which recordings are made; as the stimulus direction bisects the orientation, the effective stimulus-proportional to the cosine of orientations-varies by less than $23 \%$. The variation within a cell is harder to estimate and might be 
significant, since the lengths of stereocilia vary by more than 2-fold within a bundle. For a given displacement at the tip of the kinocilium, the angular displacement of different stereocilia can be calculated from the geometry of the bundle. In fact, the geometry is such that the variation in angular displacement for all stereocilia of a bundle is no more than a few percent. Some variation in displacement sensitivity is unavoidable, and in this respect the stimulus is less well defined than that for voltage-dependent channels.

The response time of the voltage clamp is short compared to the time course of the signals measured here. The series resistance of the chamber and of supporting cells in the epithelium has been compensated for, and thus should not produce significant delays in the measured currents. It might be thought that the geometry of hair cells causes a delay: because the receptor current seems to enter the hair cell near the tips of the stereocilia (Hudspeth, 1982), the cable properties of the cilia might be significant. From measured values for the hair cell's specific membrane resistance and capacitance and the cell body's resistance and capacitance, and from an estimated internal resistivity of the stereocilia, several independent calculations indicate a latency to 1 to $5 \mu \mathrm{sec}$ (Hudspeth, 1982). This estimate is supported by analog simulation with a network of resistors and capacitors. Delay along the equivalent cable of stereocilia should therefore not be significant in the interpretation of the present results.

\section{Models of the transduction process}

Enzymatic systems. One class of models for the transduction process involves a reversible covalent modification of a membrane channel protein. The widespread involvement of phosphorylation and methylation reactions in regulation of biological processes (Greengard, 1978, 1979; Krebs and Beavo, 1979; Springer et al., 1979; Hirata and Axelrod, 1980) has been shown to extend to some sensory systems (Hubbell and Bownds, 1979). Indeed, phosphorylation of phosphatidylinositol has been suggested to play a role in transduction by an insect mechanoreceptor (Kilian and Schacht, 1980).

One could imagine that displacement of the sterocilia activated a protein kinase or a methyl transferase, which in turn phosphorylated or methylated channel proteins to their conducting state. A continuously active phosphatase or methyl esterase could then return the channels to their nonconducting form upon termination of the stimulus. The first requirement of such a system is that it be fast enough to explain the rapid relaxations to a new equilibrium. Both activating and inactivating enzymes must have turnover rates of the order of $10^{4} \mathrm{sec}^{-1}$; carbonic anhydrase (EC $4.2 .1 .1 ; 10^{6} \mathrm{sec}^{-1}$ at $25^{\circ} \mathrm{C}$; Khalifah, 1971) and acetylcholinesterase (EC 3.1.1.7; $10^{4} \mathrm{sec}^{-1}$ at $25^{\circ} \mathrm{C}$; Wilson and Harrison, 1961) are notable examples of sufficiently fast enzymes. But in general the faster enzymes catalyze reactions that proceed moderately well without catalysis. A more realistic example in the present context is the catalytic subunit of adenosine $3^{\prime}: 5^{\prime}$-cyclic monophosphate-dependent protein kinase (EC 2.7.1.37), which has a turnover rate of only $2 \mathrm{sec}^{-1}$ at $30^{\circ} \mathrm{C}$ (Sugden et al., 1976). This is clearly inadequate to account for the speed of the responses measured here. Unless hair cells contain an enzymatic control system orders of magnitude faster than those presently understood from other tissues, it seems unlikely that transduction is mediated by such a process.

Second messengers. Another class of models for the mechanism of transduction includes those with a diffusible chemical intermediary between the last mechanical stage and the change in membrane conductance. A second messenger mechanism, in which the messenger may be $\mathrm{Ca}^{2+}$ or guanosine $3^{\prime}: 5^{\prime}$-cyclic monophosphate, has been shown to exist for rod photoreceptors (Hagins, 1972; Baylor et al., 1974; Hubbell and Bownds, 1979). Were a second messenger mechanism to underlie hair cell transduction, some of its characteristics could be deduced from the experimental data.

The latency of the response, measured as the delay between rise of the otolithic membrane signal and the rise of the fastest current onset traces, is less than $40 \mu \mathrm{sec}$ at $22^{\circ} \mathrm{C}$ (Fig.6A; Corey and Hudspeth, 1979a). The maximum distance over which a messenger could act is thus limited by diffusion rates to approximately $0.5 \mu \mathrm{m}$, assuming three-dimensional diffusion of a molecule with diffusion constant equal to $1.3 \times 10^{-5} \mathrm{~cm}^{2} / \mathrm{sec}$, as for $\mathrm{K}^{+}$ in squid axoplasm (Hodgkin and Keynes, 1953). As the conductance change occurs near the tips of the stereocilia (Hudspeth, 1982), the source of a second messenger would itself be there. The simplest activation scheme for a second messenger model would be of the form:

$$
M+C \stackrel{k_{1}^{\prime}}{\longrightarrow} M C \stackrel{k_{2}}{\longrightarrow} M C^{*}
$$

in which $M$ represents the messenger, $C$ the closed channel, and $M C^{*}$ the activated (open) channel. In this scheme the binding rate constant $k_{1}^{\prime}$ is pseudo-first order; it is a function of concentration, since $k_{1}^{\prime}=k_{1}[M]$, and thus of displacement. But $k_{2}$ is not: it represents an opening rate intrinsic to the channcl. As the opening rates have been seen to be functions of displacement, $k_{2}$ could not be rate limiting.

The fast offset of the current following a positive step puts further constraints on the model. As the equilibrium between the open and closec forms of $M C$ must be independent of bundle position in a strict second messenger model, the fast offset could occur only if unbinding is rapid. Moreover, a large unbinding rate could cause a net decrease in current only if the concentration of messenger dropped rapidly, either by diffusion or by rapid uptake. In order to explain the stable equilibrium over many milliseconds, with a concentration drop occurring over tens of microseconds, we must suppose a continuous production of messenger. We are driven to a model that requires hair bundle position to control, both continuously and instantaneously, the concentration of a messenger substance. It is difficult to imagine the implementation of such a system in molecular terms.

A further shortcoming of both enzymatic and second messenger models is that they describe intermediaries in an activation chain but do not identify the initial transduction event. The displacement-dependent activation of a kinase or methyl transferase or the production of a second messenger is not explained, so that the models 
bring us no closer to an understanding of the transduction element.

Direct coupling to the transduction channel. Another class of models involves a direct link between displacement of the stereocilia and opening of transduction channels. Displacement of the stereocilia would directly influence the energy difference between open and closed states, as does potential change for voltage-activated channels. For voltage-dependent channels, the energy difference between states depends on the electric field strength and on the difference between states of either the position of a fixed charge or of the dipole moment along the field vector. The vollage-dependent part of the energy difference, $\Delta G^{\prime}$, is:

$$
\Delta G^{\prime}=E q \Delta x \text { or } \Delta G^{\prime}=E \Delta p
$$

where $E$ is the electric field vector, $q$ the magnitude of a "gating" charge, and $\Delta x$ the difference along the field vector in the position of the charge. With the alternative scheme, $\Delta p$ is the change in dipole moment of a gating dipole. For both, the energy difference is linear with membrane potential.

In a simple model for a direct mechanical activation, the displacement of one end of an elastic linkage provides the energy difference. Here also, the energy difference is a linear function of the stimulus. As a first approximation, the linkage might be expected to obey Hooke's law; thus:

$$
G^{\prime \prime}=k d^{2}
$$

where $k$ is the spring constant and $d$ is the displacement from rest.

The elastic component of the difference in energy between two states depends on the difference, along the axis of the elastic linkage, in the two positions of a gating element:

$$
\Delta G^{\prime \prime}=k\left[d_{2}^{2}-d_{1}^{2}\right]
$$

If the distal end of the linkage is moved by a distance of $\gamma x$, proportional to bundle displacement $x$, then

$\Delta G^{\prime \prime}=k\left[\left(d_{2}+\gamma x\right)^{2}-\left(d_{1}+\gamma x\right)^{2}\right]=k\left(d_{2}^{2}-d_{1}^{2}\right)+2 k\left(d_{2}-d_{1}\right) \gamma x$

This expression is of the general form

$$
\Delta G=G_{1}-Z_{1} x
$$

where $G_{\perp}$ incorporates the first term of equation 4 as well as any intrinsic energy difference between open and closed states of the channel, and $Z_{1}$ is a displacement sensitivity. With this simple model, the energy difference between the two positions is a linear function of bundle displacement. The equilibrium distribution of channels between the open and closed states is a Boltzmann distribution, in which the proportion of channels in the open state $P_{2}$ is

$$
P_{2}=1 /(1+\exp (\Delta G / R T))
$$

The average conductance is therefore a function of displacement in a model of this sort. The rate of transitions between closed and open states is similarly a function of displacement; the opening rate $k_{12}$ depends on the height $G_{b}$ of an energy barrier to transitions:

$$
k_{12}=f \exp \left(-G_{b} / R T\right)
$$

The frequency factor $f$ is assumed to equal its theoretical maximum of $k T / h \simeq 6 \times 10^{12} \mathrm{sec}^{-1}$. The displacement sensitivity of the rate occurs because the intrinsic barrier height $G_{12}$ has added to it a proportion $\delta_{12}$ of the energy difference between states, $\Delta G$ :

$$
G_{b}=G_{12}+\delta_{12} \Delta G
$$

This is shown schematically in Figure $11 A$; Figure $11 B$ indicates the effect of a positive displacement. Thus,

$$
k_{12}=f \exp \left(-\left(G_{12}+\delta_{12}\left(G_{1}-Z_{1} x\right)\right) / R T\right)
$$

Similarly, the closing rate

$$
k_{21}=f \exp \left(-\left(G_{12}-\left(1-\delta_{12}\right)\left(G_{1}-Z_{1} x\right)\right) / R T\right)
$$

These expressions for rate constants could be condensed to forms such as $k_{12}=f \exp \left(B_{12}+A_{12} x\right)$ so that four free parameters $\left(A_{12}, A_{21}, B_{12}\right.$, and $\left.B_{21}\right)$ characterize the model (Chiu, 1977). Since the four free parameters $G_{1}, G_{12}, \delta_{12}$, and $Z_{1}$ are more directly related to the physical model, we have chosen to retain the present form.

At any time, the rate of change in $P_{2}$ is given by

$$
d P_{2} / d t=-k_{21} P_{2}+k_{12}\left(1-P_{2}\right)
$$

Following a change in $\Delta G, P_{2}$ relaxes to a new equilibrium with first-order kinetics; the time constant $\tau$ of the relaxation is

$$
\tau=1 /\left(k_{12}+k_{21}\right)
$$

If a displacement, $x$, of the bundle reduces the free energy of the open state by $Z_{1} x$, then a large positive displacement has two effects: it increases the proportion $P_{2}$ of channels in the open state, and it decreases the time constant of the approach to equilibrium (Fig. $11 B$ ). Negative displacement decreases $P_{2}$, but also decreases the time constant. Thus the dependence of the experimentally oberved time constants on displacement can be accounted for, and the sigmoidal displacement-response curve can be seen as a simple Boltzmann distribution.

This two-state model cannot account for all aspects of the data, however; it predicts neither the detailed shape of the equilibrium curve nor the second-order kinetics. The displacement-response curve is not a symmetrical sigmoid of the sort predicted by equation 6 , but saturates more gradually for positive displacements than for negative (Fig. 12). The simple model assumes a linear dependence of energy difference on displacement, described by the sensitivity constant, $Z_{1}$. If this assumption is relaxed, to allow the change in energy to be an arbitrary function of displacement, then the equilibrium curve can be fitted. The model still cannot fit the time course of the relaxation to equilibrium. A two-state model always produces a first-order relaxation that can be described by a single exponential decay curve. It cannot describe the delay in onset following a negative prepulse, or the twophase offset.

Such features in other systems have been modelled by posiling a cooperative action of identical subunits (Hodgkin and Huxley, 1952) or by including additional states in an activation sequence (Hoyt, 1963). A cooperative model produces an asymmmetric equilibrium curve and second-order kinetics, but fails to provide a quantitative fit to the data. The proportion of conductance activated 

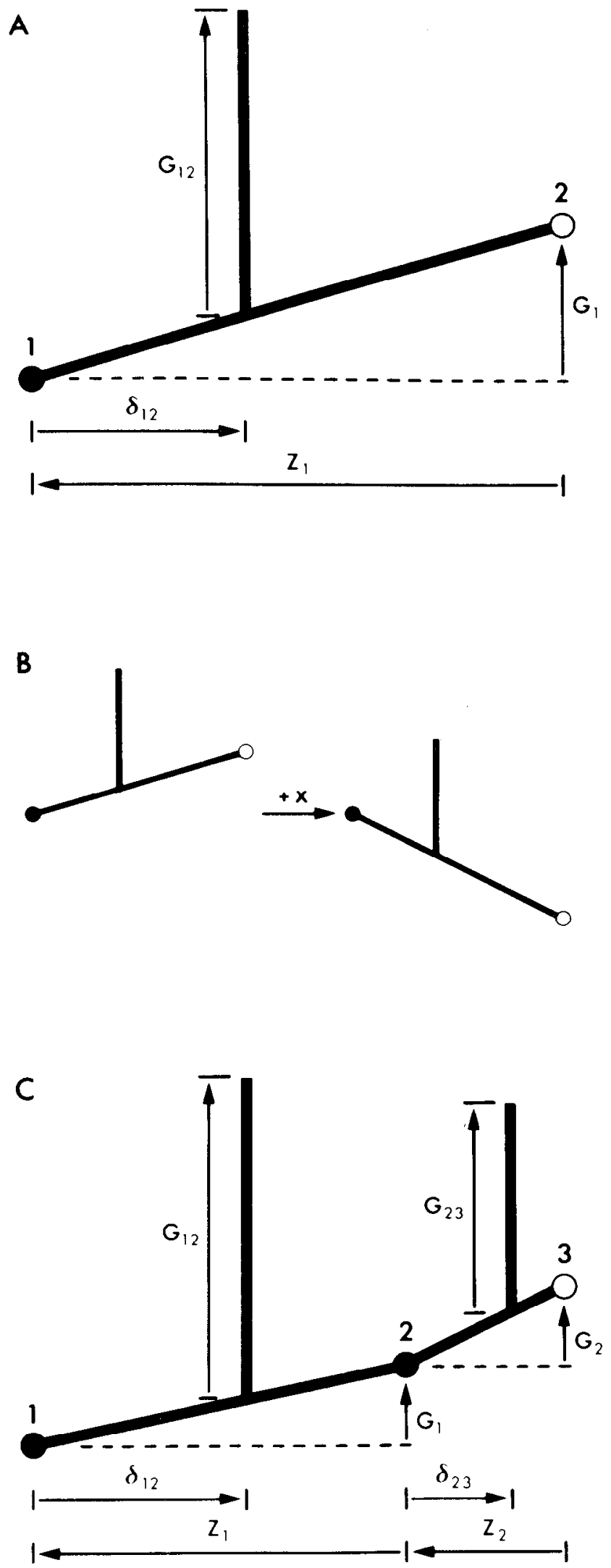

Figure 11. Schematic figures of two- and three-state directcoupling models. $A$, A simple two-state model has a nonconducting state (1) and a conducting state (2). The energy difference between them, $\Delta G$, has an intrinsic difference term $G_{1}$ and a displacement-sensitive term $Z_{1} x$. The barrier to transitions between states, of height $G_{12}$, has added to it a proportion $\delta_{12}$ of is described at any time by $P^{n}$, with $P$ as above for each of $n$ subunits. However, $P^{n}$ cannot fit the displacementresponse curve, regardless of the value chosen for $n$, unless it includes a nonlinear energy function (Fig. 11). Moreover, a $P^{n}$ model does not provide a good fit to the onset current records. While responses to steps from -0.4 $\mu \mathrm{m}$ to 0.6 to $1.0 \mu \mathrm{m}$ are fitted well by $n=1.5$, responses to steps to 0.1 or $0.2 \mu \mathrm{m}$ require an $n$ of at least 4 , and the fit is not particularly good.

Alternatively, a two-state model might be expanded by adding a second closed state (Fig. $11 C$; Corey and Hudspeth, 1980a). The explicit solution for the time course of relaxation then contains two time constants, each a function of four rate constants (Chiu, 1977). If the parameters $G_{2}, G_{23}, \delta_{23}$, and $Z_{2}$ for the second transition are allowed to vary independently, this sequential model can produce a fairly good fit both to the displacement-response curve and to the onset of the currents. The equilibrium curve is shown in Figure 12; it assumes a linear dependence of energy change on displacement. The first transition is very sensitive to displacement, with $Z_{1}=10 \mathrm{kcal} / \mathrm{mol}$ $\mu \mathrm{m}$, and the second transition is less so, with $Z_{2}=2 \mathrm{kcal} /$ mol- $\mu \mathrm{m}$. The three states are of comparable energies at rest so the open state is partially populated.

With appropriate values for the transition parameters $G_{12}, G_{23}, \delta_{12}$, and $\delta_{23}$, one can also fit the onset of the currents following a step both from rest and with a negative prepulse (Fig. 13A). In addition, the temperature dependence of the onset rates is consistent with this model. Assuming that the frequency factor $f$ is equal to its theoretical value of $k T / h$, the onset rates imply values for the barriers $G_{12}$ and $G_{23}$ of 12.5 and $12.0 \mathrm{kcal} / \mathrm{mol}$. The Arrhenius plot (Fig. 7A) gives an enthalpic contribution to the barrier heights in the range of 11 to 13 $\mathrm{kcal} / \mathrm{mol}$.

It is not possible with the three-state model to fit the offset of the current with parameter values that fit the onset (Fig. 13B). The principal deviation is the independence of the measured time constants on displacement, noted earlier, for steps to large negative bundle positions. 'The model predicts offset currents that relax increasingly more rapidly for more negative steps; this is not seen in the experimental data. This model could probably be salvaged if the energy function were allowed to be nonlinear, in particular if the state energies simply did not change beyond some negative bundle position. Even so, the offset rates should show a temperature dependence similar to that of the onset, with $G_{b}$ around $12 \mathrm{kcal} / \mathrm{mol}$, and they clearly do not (Fig. $7 B$ ). Whereas opening of transduction channels is fitted well by supposing a direct effect of bundle position on channel energy states, the

the energy difference $\Delta G$, where $0<\delta<1 . B$, Displacement of the hair bundle through distance $x$ makes the conducting state energetically more favorable than the nonconducting state. Note that stimulation also lowers the barrier for transitions from the closed to the open state and thus speeds the relaxation to a new equilibrium. $C$, A three-state model has two nonconducting states, 1 and 2 , and a conducting state 3 . Model parameters are as in $A$; here the displacement sensitivity $Z$ for each transition is represented as a distance along the (horizontal) reaction coordinate. 
closing of channels seems to be modified by an additional process.

A peculiarity of the offset of current following a positive prepulse (Fig. $4 B$ ) is that the time course of the offset is very steeply dependent on displacement, but only to a point. For displacements to levels of or below $-0.1 \mu \mathrm{m}$ (in normal apical $\mathrm{Ca}^{2+}$ ) the relaxations are completely independent of bundle position. Once the hair bundle is displaced to positions more negative than -0.1 $\mu \mathrm{m}$, it has no further influence on the amplitude or time course of the receptor current. In this respect it is as if internal mechanical linkage becomes slack. Altering apical $\mathrm{Ca}^{2+}$ changes the point of negative saturation in the displacement-response curve and, in parallel, alters the position at which the offset kinetics becomes displacement independent. Thus the negative saturation might not represent a state in which all of the transduc-

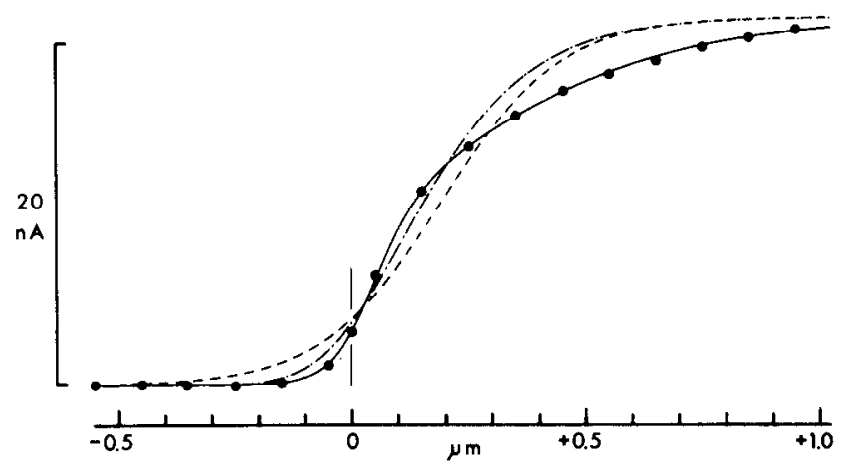

Figure 12. Fitting the displacement-response curve with functions derived from direct-coupling models. The data $(\mathbf{O}$, from Fig. $2 C$ ) are poorly fit by a simple two-state model in which $\Delta G=G_{1}-Z_{1} x$. The closest fit by eye (-- ) is with $Z_{1}$ $=4.2 \mathrm{kcal} / \mathrm{mol}-\mu \mathrm{m}$ and $G_{1}=0.82 \mathrm{kcal} / \mathrm{mol}$. Even with a twostate model raised to a power, the best fit (-.-) is far from satisfactory $\left(n=5 ; Z_{1}=3.7 \mathrm{kcal} / \mathrm{mol}-\mu \mathrm{m} ; G_{1}=0.47 \mathrm{kcal} / \mathrm{mol}\right)$. A three-state model (-) provides a very good fit, with $Z_{1}=10$ $\mathrm{kcal} / \mathrm{mol}-\mu \mathrm{m}, Z_{2}=2 \mathrm{kcal} / \mathrm{mol}-\mu \mathrm{m}, G_{1}=0.67 \mathrm{kcal} / \mathrm{mol}$, and $G_{2}$ $=0.14 \mathrm{kcal} / \mathrm{mol}$. Displacement-response curves obtained at different temperatures and $\mathrm{Ca}^{2+}$ concentrations can be fitted in nearly all cases with minor variations in these four parameters. tion channels are closed, but may instead be a point where the hair bundle's position no longer influences the channels. The effect of altering $\mathrm{Ca}^{2+}$ would be to change the point at which the linkage goes slack.

We have no direct evidence for such a mechanical linkage except insofar as it provides a consistent way of viewing several peculiarities of the response. Moreover, it seems a rather ad hoc attempt to salvage the directcoupling model. Still, the three-state, direct-coupling model goes farthest toward providing a consistent and simple model for activation of the transduction channels in hair cells, and it fails in not quantitatively predicting all aspects of the kinetic behavior. Models involving enzymatic modification or diffusible second messengers are met with more fundamental objections: in the first case to an unrealistically high turnover rate, in the second to the need for a very fast and rather baroque release and uptake system.

One noteworthy feature of probabilistic mechanisms for transduction, such as the two- and three-state models described above, is that they have no intrinsic threshold. In principle, an arbitrarily small stimulus will produce a proportionally small change in the energy difference between states, and hence some repopulation of channels from the open to the closed state, or vice versa. The ability of the system to detect such a change in the presence of noise due to other sources will then be determined by factors such as the time over which responses can be integrated. The operational threshold of the system may be set, not only by the transducer, but also by the voltage noise due to transduction of Brownian motion (Harris, 1968) and by spontaneous fluctuations in the number of open ionic channels in the presynaptic (hair cell) and postsynaptic (8th nerve fiber) membranes.

The lack of a true threshold for transduction is consistent with observations on the sensitivity of mammalian cochleas to sound. At the behavioral threshold for hearing, the motion of the cochlea's basilar membrane-and presumably of the hair bundles (Rhode and Geisler, 1966) -is about \pm 100 pm (Khanna and Leonard, 1982; Sellick et al., 1982). While sensitivity to motions of atomic dimensions might seem unlikely on the basis of a deter-
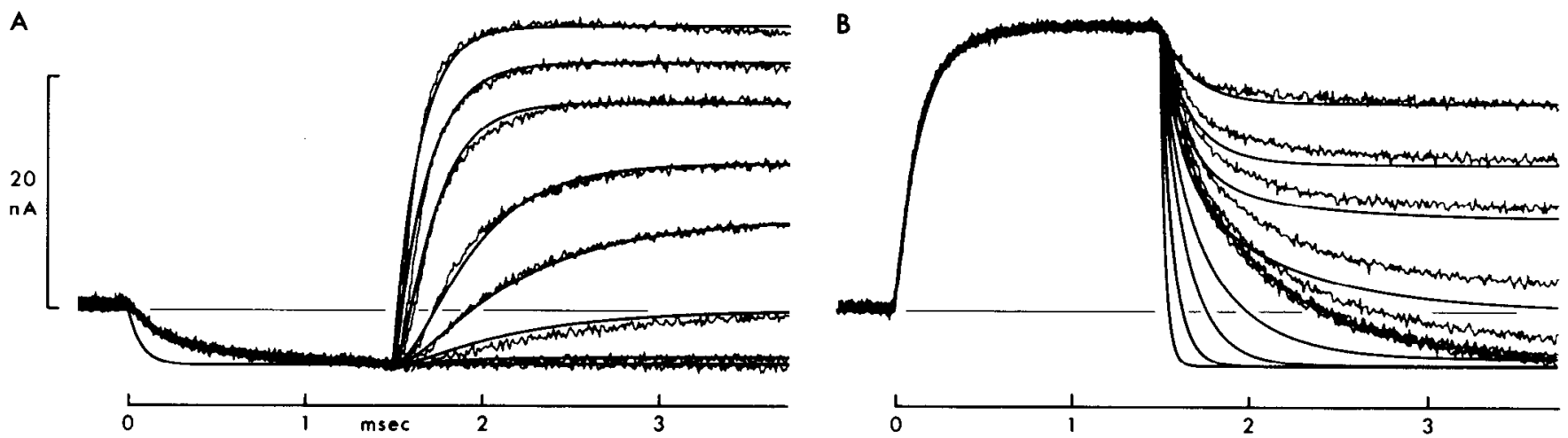

Figure 13. Fitting the relaxation kinetics with a three-state direct-coupling model. Experimental records are reproduced from Figure 4. $A$, The onset kinetics can be fitted well with the appropriate parameters; here $Z_{1}=10 \mathrm{kcal} / \mathrm{mol}-\mu \mathrm{m}, Z_{2}=2 \mathrm{kcal} / \mathrm{mol}$ $\mu \mathrm{m}, G_{1}=0.44 \mathrm{kcal} / \mathrm{mol}, G_{2}=0.23 \mathrm{kcal} / \mathrm{mol}, G_{12}=12.45 \mathrm{kcal} / \mathrm{mol}, G_{23}=12.05 \mathrm{kcal} / \mathrm{mol}, \delta_{12}=0.73$, and $\delta_{23}=0.45 . B$, The same parameters produce a poor fit to the offset kinetics. With parameters that fit the onset records in $A$ somewhat less well, most of the offset traces in $B$ can be fitted, but the agreements with the more negative displacements are still quite poor. In general the predicted offset traces are far faster than those observed. 
ministic, mechanical model for the transduction apparatus, it is compatible with a probabilistic scheme such as that offered above.

\section{References}

Baylor, D. A., A. L. Hodgkin, and T. D. Lamb (1974) The electrical response of turtle cones to flashes and steps of light. J. Physiol. (Lond.) 242: 685-727.

Bosher, S. K., and R. L. Warren (1978) Very low calcium content of cochlear endolymph, an extracellular fluid. Nature 273: 377-378.

Budak, B. M., A. A. Samarskii, and A. N. Tikhonov (1964) A Collection of Problems on Mathematical Physics, pp. 50, 321-322, Macmillan Publishing Co., Inc., New York.

Chiu, S. Y. (1977) Inactivation of sodium channels: Second order kinetics in myelinated nerve. J. Physiol. (Lond.) 273: 573-596.

Chiu, S. Y., J. M. Ritchie, R. B. Rogart, and D. Stagg (1979) A quantitative description of membrane currents in rabbit myelinated nerve. J. Physiol. (Lond.) 292: 149-166.

Corey, D. P., and A. J. Hudspeth (1979a) Response latency of vertebrate hair cells. Biophys. J. 26: 499-506.

Corey, D. P., and A. J. Hudspeth (1979b) Ionic basis of the receptor potential in a vertebrate hair cell. Nature 281: 675677.

Corey, D. P., and A. J. Hudspeth (1980a) Gating kinetics of the transduction element in a vertebrate hair cell: Evidence for a three-state model. Soc. Neurosci. Abstr. 6: 96 .

Corey, D. P., and A. J. Hudspeth (1980b) Mechanical stimulation and micromanipulation with piezoelectric bimorph elements. J. Neurosci. Methods 3: 183-202.

Corey, D. P., and A. J. Hudspeth (1983) Analysis of the microphonic potential of the bullfrog's sacculus. J. Neurosci. 3: 977-986.

Eatock, R. A., D. P. Corey, and A. J. Hudspeth (1979) Adaptation in a vertebrate hair cell: Stimulus-induced shift of the operating range. Soc. Neurosci. Abstr. 5: 19.

Greengard, P. (1978) Phosphorylated proteins as physiological effectors. Science 199: 146-152.

Greengard, P. (1979) Cyclic nucleotides, phosphorylated proteins, and the nervous system. Fed. Proc. 38: 2208-2217.

Hagins, W. A. (1972) The visual process: Excitatory mechanisms in the primary receptor cells. Annu. Rev. Biophys. Bioeng. 1: 131-158.

Harris, G. G. (1968) Brownian motion in the cochlear partition. J. Acoust. Soc. Am. 44: 176-186.

Hille, B. (1971) Voltage clamp studies on myelinated nerve fibers. In Biophysics and Physiology of Excitable Membranes, W. J. Adelman, ed., pp. 230-246, Van Nostrand Reinhold, New York.

Hille, B., A. M. Woodhull, and B. I. Shapiro (1975) Negative surface charge near sodium channels of nerve: Divalent ions, monovalent ions, and pH. Philos. Trans. R. Soc. Lond. (Biol.) 270: 301-318.

Hillman, D. E., and E. R. Lewis (1971) Morphological basis for a mechanical linkage in otolithic receptor transduction in the frog. Science 174: 416-419.

Hirata, F., and J. Axelrod (1980) Phospholipid methylation and biological signal transmission. Science 209: 1082-1090.

Hodgkin, A. L., and A. F. Huxley (1952) A quantitative description of membrane current and its application to conduction and excitation in nerve. J. Physiol. (Lond.) 117: 500-544.

Hodgkin, A. L., and R. D. Keynes (1953) The mobility and diffusion coefficient of potassium in giant axons from Sepia.
J. Physiol. (Lond.) 119: 513-528.

Hoyt, R. C. (1963) The squid giant axon. Mathematical models. Biophys. J. 3: 339-431.

IIubbell, W. L., and M. D. Bownds (1979) Visual transduction in vertebrate photoreceptors. Annu. Rev. Neurosci. 2: 17-34.

Hudspeth, A. J. (1982) Extracellular current flow and the site of transduction by vertebrate hair cells. J. Neurosci. 2: 1-10.

Hudspeth, A. J., and D. P. Corey (1977) Sensitivity, polarity, and conductance change in the response of vertebrate hair cells to controlled mechanical stimuli. Proc. Natl. Acad. Sci. U. S. A. 74: 2407-2411.

Hudspeth, A. J., and R. Jacobs (1979) Stereocilia mediate transduction in vertebrate hair cells. Proc. Natl. Acad. Sci. U. S. A. 76: 1506-1509.

Khalifah, R. G. (1971) The carbon dioxide hydration activity of carbonic anhydrase. J. Biol. Chem. 246: 2561-2573.

Khanna, S. M., and D. G. B. Leonard (1982) Basilar membrane tuning in the cat cochlea. Science 215: 305-306.

Kilian, P. I., and J. Schacht (1980) Sound stimulates labeling of polyphosphoinositides in the auditory organ of the noctuid moth. J. Neurochem. 34: 709-712.

Krebs, E. G., and J. A. Beavo (1979) Phosphorylation-dephosphorylation of enzymes. Annu. Rev. Biochem. 48: 923-959.

Lewis, C. A. (1979) Ion-concentration dependence of the reversal potential and the single channel conductance of ion channels at the frog neuromuscular junction. J. Physiol. (Lond.) 286: 417-445.

McLaughlin, S. G. A., G. Szabo, and G. Eisenman (1971) Divalent ions and the surface potential of charged phospholipid membranes. J. Gen. Physiol. 58: 667-687.

Muller, R. V., and A. Finkelstein (1972) The effect of surface charge on the voltage-dependent conductance induced in thin lipid membranes by monazomycin. J. Gen. Physiol. 60: 285306.

Rhode, W. S., and C. D. Geisler (1966) Model of the displacement between opposing points on the tectorial membrane and reticular lamina. J. Acoust. Soc. Am. 42: 185-190.

Roos, A., and W. F. Boron (1981) Intracellular pH. Physiol. Rev. 61: 296-434.

Sabersky, R. H., A. J. Acosta, and E. G. Hauptmann (1971) Fluid Flow, a First Course in Fluid Mechanics, Ed. 2, pp. 10-11, 58-60, Macmillan Publishing Co., Inc., New York.

Sales, G., and D. Pye (1974) Ultrasonic Communication by Animals, Chapman and Hall, London.

Sand, O. (1975) Effects of different ionic environments on the mechano-sensitivity of lateral line organs in the mudpuppy. J. Comp. Physiol. 102: 27-42.

Sellick, P. M., R. Patuzzi, and B. M. Johnstone (1982) Measurement of basilar membrane motion in the guinea pig using the Mössbauer technique. J. Acoust. Soc. Am. 72: 131-141.

Shotwell, S. L., R. Jacobs, and A. J. Hudspeth (1981) Directional sensitivity of individual vertebrate hair cells to controlled deflection of hair bundles. Ann. N. Y. Acad. Sci. 374: 1-10.

Springer, M. S., M. F. Goy, and J. Adler (1979) Protein methylation in behavioural control mechanisms and in signal transduction. Nature 280: 279-284.

Sugden, P. H., L. A. Holladay, E. M. Reimann, and J. D. Corbin (1976) Purification and characterization of the catalytic subunit of adenosine $3^{\prime}: 5^{\prime}$-cyclic monophosphate-dependent protein kinase from bovine liver. Biochem. J. 159: 409-422.

von Békésy, G. (1960) Experiments in Hearing, McGraw-Hill, New York.

Wilson, I. B., and M. A. Harrison (1961) Turnover number of acetylcholinesterase. J. Biol. Chem. 236: 2292-2295. 